\title{
Prediction of the Load Carrying Capacity of Elevated Steel Fibre Reinforced Concrete Slabs
}

\author{
Hamidreza Salehian ${ }^{1}$, Joaquim A.O. Barros ${ }^{2}$ \\ 1- Assistant Professor, Seismic Geotechnical and High Performance Concretes \\ Research Centre, Department of Civil Engineering, Semnan Branch, Islamic Azad \\ University, Semnan, Iran, e-mail: hrsalehian@semnaniau.ac.ir (corresponding \\ author) \\ 2- Full Professor, ISISE, Department of Civil Engineering, University of Minho, \\ Guimarães, Portugal, e-mail: barros@civil.uminho.pt
}

\begin{abstract}
A novel methodology is developed for predicting the load carrying capacity of elevated steel fibre reinforced concrete (E-SFRC) slab systems. In the proposed approach the depth of slab's cross section is discretized into several layers, and the number of steel fibres per each layer is determined by considering the distribution of fibres along the depth of cross section. This information, together with the one obtained from the threepoint notched beam bending tests performed on four series of SFRC made of different concrete strength class and content of fibres, have provided the stress-crack width laws for defining the post-cracking behaviour of each layer. These constitutive laws are implemented in a numerical model developed based on the moment-rotation approach for determining the positive and negative resisting bending moment of the slab's unit width cross section. By using the yield line theory, the load carrying capacity of ESFRC slab is predicted for the most current load conditions. Predictive performance of the proposed methodology is assessed comparing to the results recorded in experiment and the ones obtained by the numerical simulation. Finally the developed model is utilised in a parametric study to evaluate the influence of parameters that affect the load-carrying capacity of E-SFRC slabs.
\end{abstract}

Keywords: Elevated slabs, steel fibre reinforced concrete, load carrying capacity, yield line theory, fibre distribution. 


\section{Introduction}

Despite the noticeable potentialities of steel fibres as the fundamental reinforcement of slabs and shell type elements [1] and elevated steel fibre reinforced concrete (E-SFRC) slabs [2, 3], there is still a lack of a reliable and relatively simple approach for a comprehensive design of these types of SFRC applications. Elevated slab is considered a flat slab supported on reinforced concrete columns that can be made by SFRC, with or without self-compacting requisites, where the unique conventional reinforcement is placed at the bottom region of the slab's cross section, in the alignment of the columns in order to avoid the occurrence of progressive collapse [4]. Traditional approaches for the design of reinforced concrete slabs often neglect the contribution of the postcracking tensile capacity of concrete. In case of SFRC, mainly when using a relatively high content of steel fibres, these design strategies underestimate noticeably the load carrying capacity of structures with redundant support conditions $[5,6]$, such is the general case of E-SFRC slabs [7]. The ultimate load of reinforced concrete slabs can be determined by the yield line theory (YLT) [8]. The YLT was first presented by Ingerslev [9] and later extended by Johansen [10,11]. In this theory it is assumed that the steel reinforcement crossing a yield line is fully yielded at failure, and the resisting bending moment of the slab's cross section is uniformly distributed along the yield lines. The YLT was later extended to the design of fibre reinforced concrete (FRC) slabs supported on soil by considering the resisting bending moment of the slab's cross section corresponding to a certain average crack width or curvature and adopting the contribution of post-cracking tensile capacity of FRC $[8,12]$. In the case of E-SFRC slabs, since the longitudinal reinforcement is almost totally substituted by discrete fibres, the plastic resisting bending moment of the slab's cross section is effectively influenced by the volume fraction and dispersion of fibres $[13,14]$. In the present paper a novel methodology is developed capable of predicting the load carrying capacity of ESFRC slab based on the YLT, in which volume fraction of fibres and dispersion of fibres along the depth of the slab's cross section are taken into consideration. These are the most relevant parameters that may influence the post-cracking behaviour of the SFRC in a material point of view. Predictive performance of the proposed methodology is assessed comparing to the results recorded in experiment and the ones obtained by the numerical simulation. Advanced numerical simulations demonstrated that when a correlation between fibre reinforcement mechanisms and the fracture energy of the 
SFRC is assured, by the increase of the load carrying capacity and ductility of E-SFRC slabs with the fracture energy, being possible to transform a brittle punching failure mode in a ductile flexural failure one [15]. In this regards, it was experimentally revealed that E-SFRC slabs fail mainly in bending [2, 16-18], and punching failure only occurs when relatively high percentage of conventional reinforcement is used [19], which is not the case of the E-SFRC treated in the present work. Therefore, in the model developed, punching failure is assumed not to occur.

\section{Yield line theory applied to E-SFRC}

\subsection{Uniformly distributed load}

When subjected to uniformly distributed loads, an elevated slab is designed separately in two orthogonal alignments [20]. According to the yield line theory, the dominant ultimate failure mode of the interior and corner panels of an elevated slab under uniformly distributed load can be represented by the crack patterns depicted in Fig. 1(a) and (b), respectively.

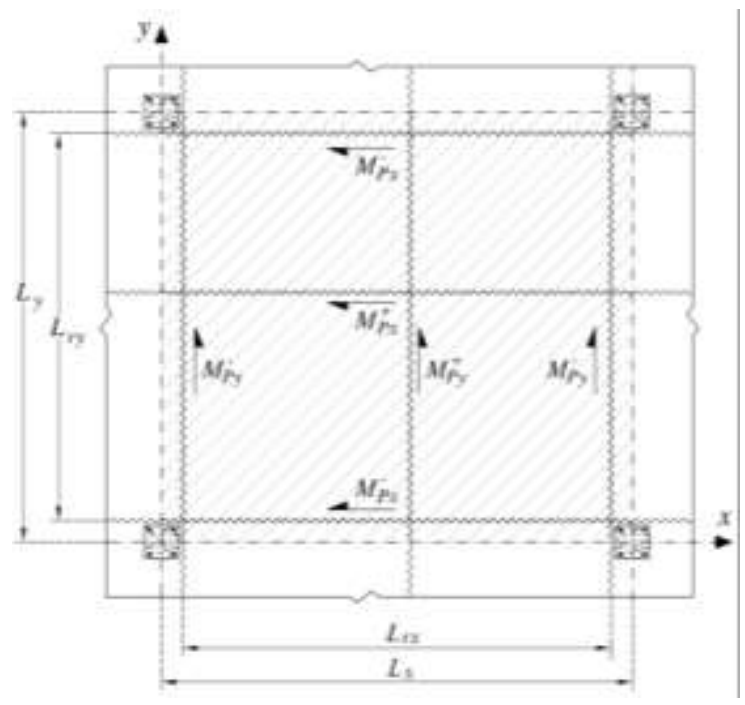

(a)

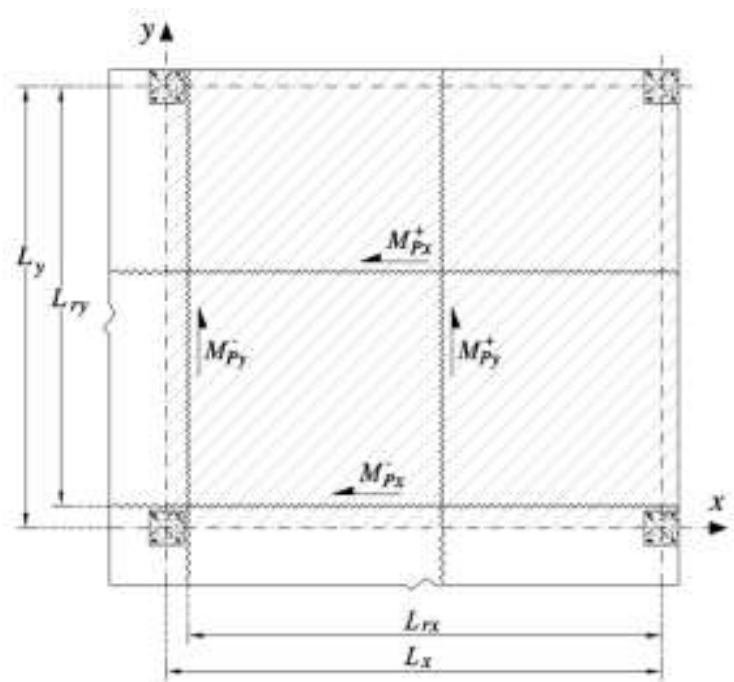

(b)

Fig. 1: Yield line patterns of (a) interior and (b) corner panel of E-SFRC slab under uniformly distributed load

The interior panel has continuity on its all borders, while in the corner panel the two free borders are assumed providing simply support conditions, materialised by a borderembedded beam supported in the adjacent columns. 
By adopting the principles of the YLT, the ultimate uniformly distributed load of the interior and corner panels of the E-SFRC slab is determined by Eqs. (1) and (2), respectively, whose deductions are presented in appendix A and B:

$$
\begin{aligned}
& q_{u l t, i n t}=\min \left[\frac{8 M_{P x}^{+}\left(1+\varphi_{h x}\right)}{L_{r y}{ }^{2}}, \frac{8 M_{P y}^{+}\left(1+\varphi_{h y}\right)}{L_{r x}{ }^{2}}\right] \\
& q_{u l t, c o r}=\min \left[\frac{2 M_{P x}^{+}\left(\sqrt{\left(1+\varphi_{h x}\right)}+1\right)^{2}}{L_{r y}{ }^{2}}, \frac{2 M_{P y}^{+}\left(\sqrt{\left(1+\varphi_{h y}\right)}+1\right)^{2}}{L_{r x}{ }^{2}}\right]
\end{aligned}
$$

In the equations above, $M_{P x}^{+}$and $M_{P y}^{+}$are the positive resisting bending moment of the slab per unit width cross section along the $x$ and $y$ directions, respectively (Fig. 1), herein abbreviated by the plastic moment. The positive bending moment is assumed to impose tensile strains on the slab's bottom surface. In Eqs. (1) and (2), $\varphi_{h x}$ and $\varphi_{h y}$ are the ratio of the negative to the positive plastic moment of the slab's unit width cross section along the $x$ and $y$ direction, respectively. Furthermore, $L_{r x}$ and $L_{r y}$ are the effective lengths of the slab's span in the $x$ and $y$ directions, respectively, representing the distance between two adjacent negative yield lines in the interior slab panel, determined according to schematic representation of Fig. 2 [20, 21]. In the corner panel the $L_{r x}$ and $L_{r y}$ are the distance in $x$ and $y$ directions, respectively, between the corresponding negative yield line and the opposite axis just close to the slab's free edge (Fig. 1b).

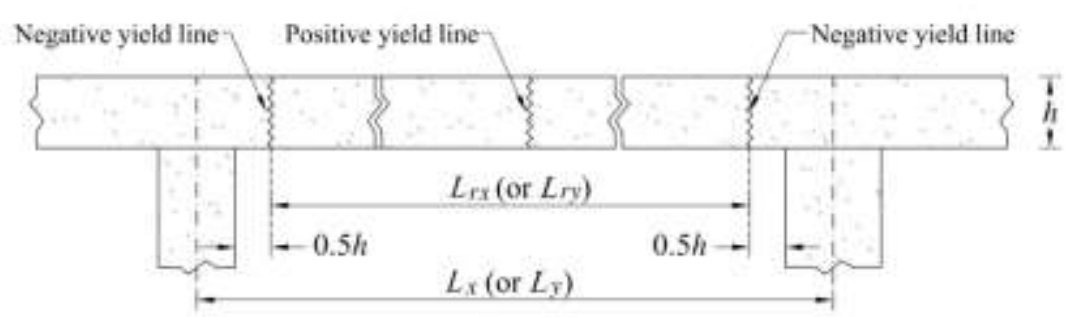

Fig. 2: Position of the negative yield lines of panel subjected to uniform load

\subsection{Quasi-point load}

The ultimate crack pattern of an interior and a corner panel of an E-SFRC slab under a load uniformly distributed in a relatively small area, designated herein by quasi-point 
load, can be represented by the pattern of yield lines depicted in Fig. 3(a) and (b), respectively. These patterns comprise radial positive yield lines (visible at the slab's bottom surface in consequence of the positive plastic bending moment), and a circumferential negative yield line (visible at the slab's top surface in consequence of the negative plastic bending moment). In case of corner panel, a half sector of the negative yield line is considered due to the simply support conditions assumed for the free borders as observed in experiment $[2,3]$.

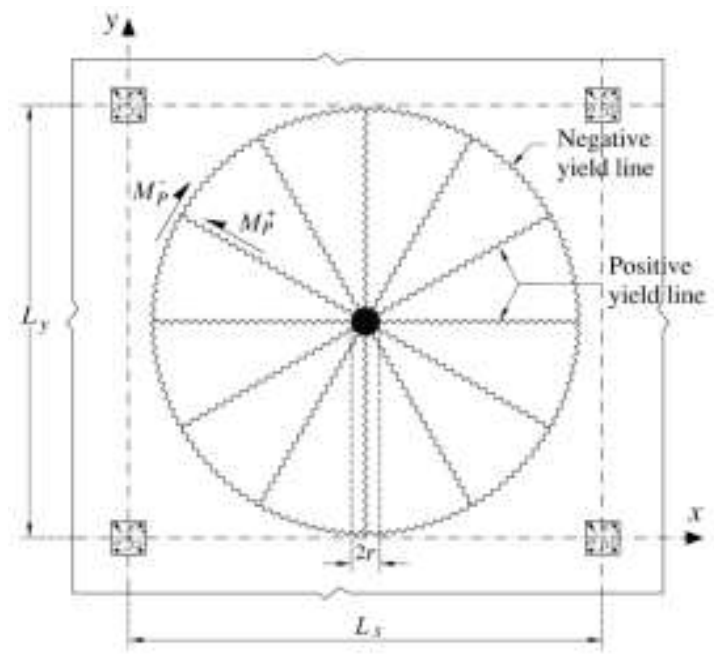

(a)

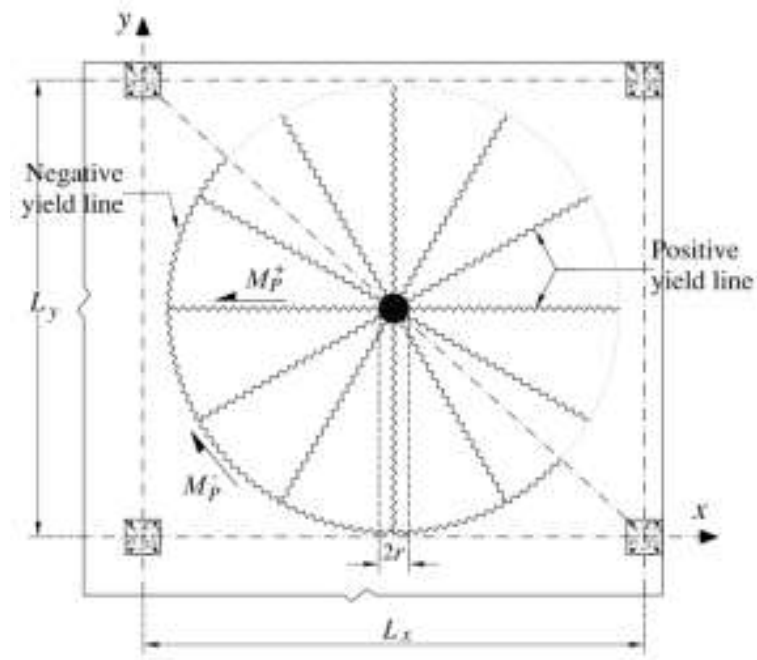

(b)

Fig. 3: Yield line patterns for (a) interior and (b) corner panel of E-SFRC slab under quasi-point load

By adopting the principles of the YLT, the ultimate quasi-point load that can be applied to the interior and corner panels ( $P_{u l t \text {,int }}$ and $P_{u l t, c o r}$, respectively) are determined by Eqs. (3) and (4), being their deduction available in appendix C and D, respectively:

$$
\begin{aligned}
P_{u l t, \mathrm{int}} & =\frac{2 \pi M_{P}^{+}\left(1+\varphi_{h}\right)}{\left(1-\frac{2}{3} \times \frac{r}{R}\right)} \\
P_{u l t, c o r} & =\frac{2 \pi M_{P}^{+}\left(1+0.5 \varphi_{h}\right)}{\left(1-\frac{2}{3} \times \frac{r}{R}\right)}
\end{aligned}
$$

where $r$ is the radius of the quasi-point load, and $R$ is the radius of the negative yield line that can be determined by the following equation: 


$$
R=\sqrt{\frac{L_{x} L_{y}}{\pi}}
$$

\section{Distribution of fibres along the height of slab's cross section}

In the case of E-SFRC slabs, when a homogeneous distribution of fibres is considered, the positive and negative plastic moments of the slab's cross section in the $x$ and $y$ direction are the same. In this case the equal $\varphi_{h x}$ and $\varphi_{h y}$ parameters can be substituted by the general designation of $\varphi_{h}$. This is a simplified assumption of the reality, since experimental research on the influence of the casting procedure of SFRC has demonstrated a tendency of fibres to line up perpendicularly to the concrete radial flow [22]. Furthermore, experimental research reveals a tendency for the increase of the percentage of steel fibres along the depth of the cross section, mainly when high vibration procedure is used [23]. The distribution of steel fibres along the height of an E-SFRC slab's cross section can be evaluated by the fibres segregation degree parameter determined by the following equation [24]:

$$
\xi_{\text {seg }}=\frac{1}{h N_{f}} \sum_{j=1}^{N_{f}} Z_{j}
$$

where $Z_{j}$ is the coordinate of the gravity centre of the $j^{\text {th }}$ fibre with respect to the upper side of the section, and $N_{f}$ is the total number of fibres crossing the $h \times b$ cross section (Fig. 4). When fibres are distributed uniformly, a value of $\xi_{\text {seg }}$ equal to 0.5 is determined by Eq. (6). The $\xi_{\text {seg }}$ parameter tends to the unity by increasing the number of steel fibres towards the bottom part of the section. 


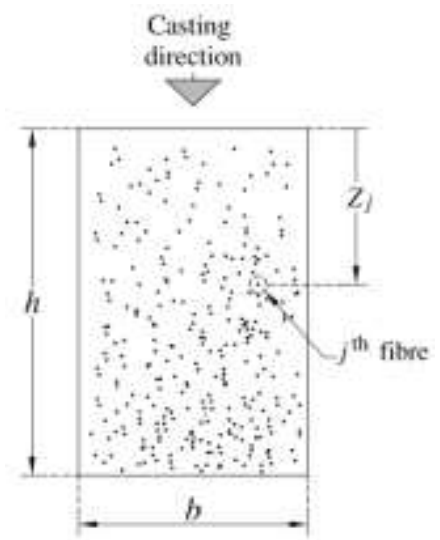

Fig. 4: Segregation of fibres along the height of the slab's cross section

In practical applications, the fibres segregation degree on the E-SFRC cross section is influenced by the rheological properties of the SFRC, casting methodology, and the height of the slab's cross section. Which can be assessed by an image analysis technique [25-27] applied to representative samples.

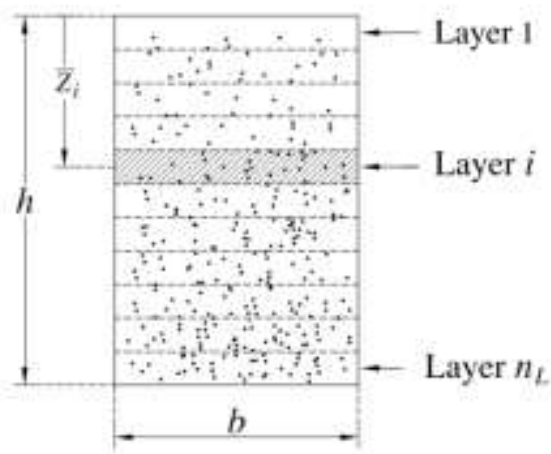

(a)

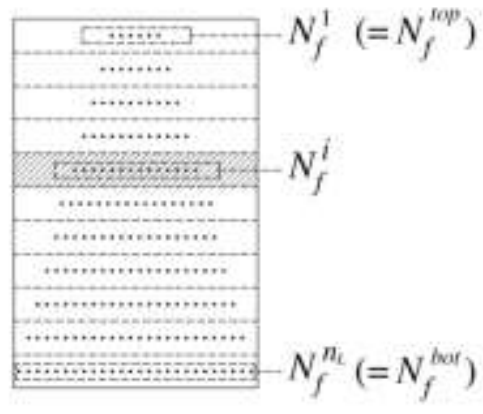

(b)

Fig. 5: (a) Layering the cross section along its height and (b) number of fibres per each layer

In the developed methodology, for evaluation of the influence of the fibres segregation on the load carrying capacity of the E-SFRC slab, the height of the slabs' cross section is discretized into $n_{L}$ layers of thickness $\Delta h\left(=h / n_{L}\right)$. The layers are enumerated from the top to the bottom, as depicted in Fig. 5(a), regarding which Eq. (6) can be rewritten as: 


$$
\xi_{\text {seg }}=\frac{1}{h N_{f}} \sum_{i=1}^{n_{L}}\left(N_{f}^{i} \bar{Z}_{i}\right)
$$

where $N_{f}^{i}$ indicates the number of fibres positioned in the generic $i^{\text {th }}$ layer, and $\bar{Z}_{i}$ is the depth of the middle surface of the $i^{\text {th }}$ layer. Note that for the sake of simplicity, it is assumed the cross section is discretized in layers of small thickness that can be two times the maximum size of aggregates. Therefore the fibres of each layer can be assumed at the middle height of the layer, as schematised in Fig. 5(b). By assuming layers of equal small thickness, $\Delta h$, Eq. (7) is reduced to the following one:

$$
\xi_{\text {seg }}=\frac{\Delta h}{h N_{f}} \sum_{i=1}^{n_{L}} N_{f}^{i}(i-0.5)
$$

Furthermore, by considering a uniform increase in the number of fibres from the top to the bottom layers of the section, $N_{f}^{i}$ can be determined by the following equation:

$$
N_{f}^{i}=\left(\frac{i-1}{n_{L}-1}\right) N_{f}^{b o t}+\left(1-\frac{i-1}{n_{L}-1}\right) N_{f}^{t o p}
$$

where $N_{f}^{t o p}$ and $N_{f}^{b o t}$ are the number of fibres of the top layer $(i=1)$ and the bottom layer ( $i=n_{L}$ ), respectively (Fig. 5b). Substituting $N_{f}^{i}$ determined by Eq. (9) into Eq. (8) yields:

$$
\begin{aligned}
& \xi_{\text {seg }} h N_{f}= \\
& N_{f}^{b o t}\left[\Delta h \sum_{i=1}^{n_{L}}(i-0.5)\left(\frac{i-1}{n_{L}-1}\right)\right]+N_{f}^{t o p}\left[\Delta h \sum_{i=1}^{n_{L}}(i-0.5)\left(1-\frac{i-1}{n_{L}-1}\right)\right]
\end{aligned}
$$

On the other hand, the total number of fibres crossing the section is equal to the summation of the number of fibres of each layer:

$$
N_{f}=\sum_{i=1}^{n_{L}} N_{f}^{i}
$$

Substituting $N_{f}^{i}$ from Eq. (9) into Eq. (11) results: 


$$
N_{f}=N_{f}^{b o t} \sum_{i=1}^{n_{L}}\left(\frac{i-1}{n_{L}-1}\right)+N_{f}^{t o p} \sum_{i=1}^{n_{L}}\left(1-\frac{i-1}{n_{L}-1}\right)
$$

Eqs. (10) and (12) constitute a $2 \times 2$ system of equations (13), whose intervening coefficients are defined by Eqs. (14) to (19):

$$
\begin{aligned}
& {\left[\begin{array}{ll}
a_{11} & a_{12} \\
a_{21} & a_{22}
\end{array}\right]\left[\begin{array}{l}
N_{f}^{b o t} \\
N_{f}^{t o p}
\end{array}\right]=\left[\begin{array}{l}
b_{1} \\
b_{2}
\end{array}\right]} \\
& a_{11}=\sum_{i=1}^{n_{L}}\left(\frac{i-1}{n_{L}-1}\right) \\
& a_{12}=\sum_{i=1}^{n_{L}}\left(1-\frac{i-1}{n_{L}-1}\right) \\
& a_{21}=\Delta h \sum_{i=1}^{n_{L}}(i-0.5)\left(\frac{i-1}{n_{L}-1}\right) \\
& a_{22}=\Delta h \sum_{i=1}^{n_{L}}(i-0.5)\left(1-\frac{i-1}{n_{L}-1}\right) \\
& b_{1}=N_{f} \\
& b_{2}=\xi_{\text {seg }} h N_{f}
\end{aligned}
$$

The total number of fibres may cross a general section of Fig. 4 can be obtained by the following equation:

$$
N_{f}=(b \times h) N_{f}^{1 x 1} \quad(b \text { and } h \text { in } \mathrm{mm})
$$

where $N_{f}^{1 x 1}$ is the total number of fibres crossing a $1 \times 1$ area of the slab's cross section, which can be estimated by the following equation [28]:

$$
N_{f}^{1 x 1}=\frac{4 V_{f}}{\pi d_{f}^{2}} \lambda \quad\left(d_{f} \text { in } \mathrm{mm}\right)
$$


where $V_{f}$ is the volume fraction of fibres, $d_{f}$ is the fibre's diameter, and $\lambda$ is the fibre efficiency factor [29]. Theoretically, in a one-dimensional dispersion, fibres are entirely aligned with the sample length, and the $\lambda$ parameter approaches the unitary value [3032]. In the case of thin shell elements, where the height of the section is small enough, dispersion of fibres is dominantly two-dimensional in plane. In this case, the fibre efficiency factor is equal to $2 / \pi$ [29]. Finally, for the general three-dimensional distribution of fibres, the values of $\lambda$ parameter of $0.5,1 / \pi$, and $(2 / \pi)^{2}$ have been proposed in the literature [32]. It is noted, however, that the actual number of fibres crossing a unit area is a random variable that should be calibrated regarding the type and geometry of the used fibres, as well as the casting methodology.

By adopting the total number of fibres crossing the section $\left(N_{f}\right)$ and the degree of fibres segregation $\left(\xi_{\text {seg }}\right.$ ) estimated from the representative samples, $N_{f}^{\text {top }}$ and $N_{f}^{\text {bot }}$ are determined by Eq. (13), by which the total number of fibres crossing the generic $i^{\text {th }}$ layer $\left(N_{f}^{i}\right)$ is obtained by Eq. (9).

\section{Influence of the number of fibres on the post-cracking response of SFRC}

The influence of the number of fibres on the post-cracking response of SFRC was evaluated in a test programme carried out on four series of SFRCs designated by C15$f 45, \mathrm{C} 30-f 45, \mathrm{C} 25-f 60$, and C45-f90. The numbers after letters " $\mathrm{C}$ " and " $f$ " represent, respectively, the target average compressive strength for the SFRC at an age of 28 days in $\mathrm{MPa}$, and the content of fibres in kilogram per concrete cubic meter. The SFRCs were developed by adopting a three-step mixing method proposed by Barros, Pereira [33]. The proportions of the constituents of each series of the developed SFRCs as well as type and geometry of the used fibres are detailed in Table 1. 
Table 1: Composition of the developed SFRCs (per $1 \mathrm{~m}^{3}$ )

\begin{tabular}{llcccc}
\hline SFRC indication & & C15-f45 & $C 30-f 45$ & $C 25-f 60$ & $C 45-f 90$ \\
\hline Target compressive strength & {$[\mathrm{MPa}]$} & 15 & 30 & 25 & 45 \\
Cement & {$[\mathrm{kg}]$} & 220 & 300 & 350 & 423 \\
Water & {$[\mathrm{kg}]$} & 105 & 140 & 160 & 144 \\
Water-to-cement ratio & {$[-]$} & 0.48 & 0.47 & 0.46 & 0.34 \\
Superplasticiser & {$[\mathrm{kg}]$} & 6.08 & 5.70 & 9.50 & 5.92 \\
Limestone filler & {$[\mathrm{kg}]$} & - & - & - & 362 \\
Fly-ash & {$[\mathrm{kg}]$} & 100 & 200 & 150 & - \\
Fine river sand & {$[\mathrm{kg}]$} & 437 & 301 & 233 & 220 \\
Coarse river sand & {$[\mathrm{kg}]$} & 693 & 755 & 698 & 671 \\
Crushed granite & {$[\mathrm{kg}]$} & 615 & 503 & 580 & 491 \\
VMA ${ }^{\text {a }}$ & {$[\mathrm{g}]$} & 22 & - & 22 & - \\
\hline Fibre type & - & HESF1 & HESF2 & HESF1 & HESF1 \\
Supplier & - & IBERMIX & RADMIX & IBERMIX & IBERMIX \\
Content & {$\left[\mathrm{kg} / \mathrm{m}^{3}\right]$} & 45 & 45 & 60 & 90 \\
Volume fraction & {$[\%]$} & 0.6 & 0.6 & 0.8 & 1.1 \\
Fibre's length & {$[\mathrm{mm}]$} & 35 & 30 & 35 & 35 \\
Fibre's diameter & {$[\mathrm{mm}]$} & 0.55 & 0.40 & 0.55 & 0.55 \\
Aspect ratio & - & 63 & 75 & 63 & 63 \\
Tensile Strength & {$[\mathrm{MPa}]$} & 1300 & 1000 & 1300 & 1300 \\
\hline
\end{tabular}

a VMA: Viscosity modifying admixture

${ }^{\mathrm{b}}$ HESF: Hooked end steel fibres

The average compressive strength of the SFRCs at an age of 28 days $\left(f_{c m}\right)$ are summarised in Table 2. The $f_{c m}$ was obtained by performing compressive tests with cylinder specimens according to EN 206-1 [34]. In Table 2 are also included the average tensile strength $\left(f_{c t m}\right)$ SFRCs $\left(E_{c m}\right)$ determined by Eqs. (22) and (23), respectively [35]:

$$
\begin{aligned}
& f_{c t m}= \begin{cases}0.30 f_{c k}^{2 / 3} & {[\text { for concrete class } \leq C 50 / 60]} \\
2.12 \ln \left(1+f_{c m} / 10\right) & {[\text { for concrete class }>C 50 / 60]}\end{cases} \\
& E_{c m}=21.5\left(\frac{f_{c m}}{10}\right)^{1 / 3}\left[f_{c m} \text { in } \mathrm{MPa}, E_{c m} \text { in } \mathrm{GPa}\right]
\end{aligned}
$$


Table 2: Material properties of the SFRCs

\begin{tabular}{lccc}
\hline $\begin{array}{l}\text { FRC } \\
\text { indication }\end{array}$ & $\begin{array}{c}f_{c m} \\
{[\mathrm{MPa}]}\end{array}$ & $\begin{array}{c}f_{c t m} \\
{[\mathrm{MPa}]}\end{array}$ & $\begin{array}{c}E_{c m} \\
{[\mathrm{GPa}]}\end{array}$ \\
\hline C15- $f 45$ & 13.12 & 1.31 & 23.31 \\
C30- $f$ 45 & 26.18 & 2.54 & 29.63 \\
C25- $f 60$ & 23.57 & 1.74 & 28.62 \\
C45- $f 90$ & 44.42 & 2.53 & 35.23 \\
\hline
\end{tabular}

By following recommendations of the fib Model Code 2010 [35], the post-cracking response of the developed SFRCs was characterised by performing the three-point notched beam bending tests (TBT) according to the test setup schematised in Fig. 6. For each series of SFRC, the TBT was performed on ten prismatic beams with $600 \mathrm{~mm}$ length and $150 \times 150 \mathrm{~mm}^{2}$ cross section. To promote crack localisation at the loaded section, a notch was executed in the mid-length of a lateral side, in parallel to the casting direction. The width and depth of the notch were $5 \mathrm{~mm}$ and $25 \mathrm{~mm}$, respectively, in agreement with the recommendations of fib Model Code 2010 [35].

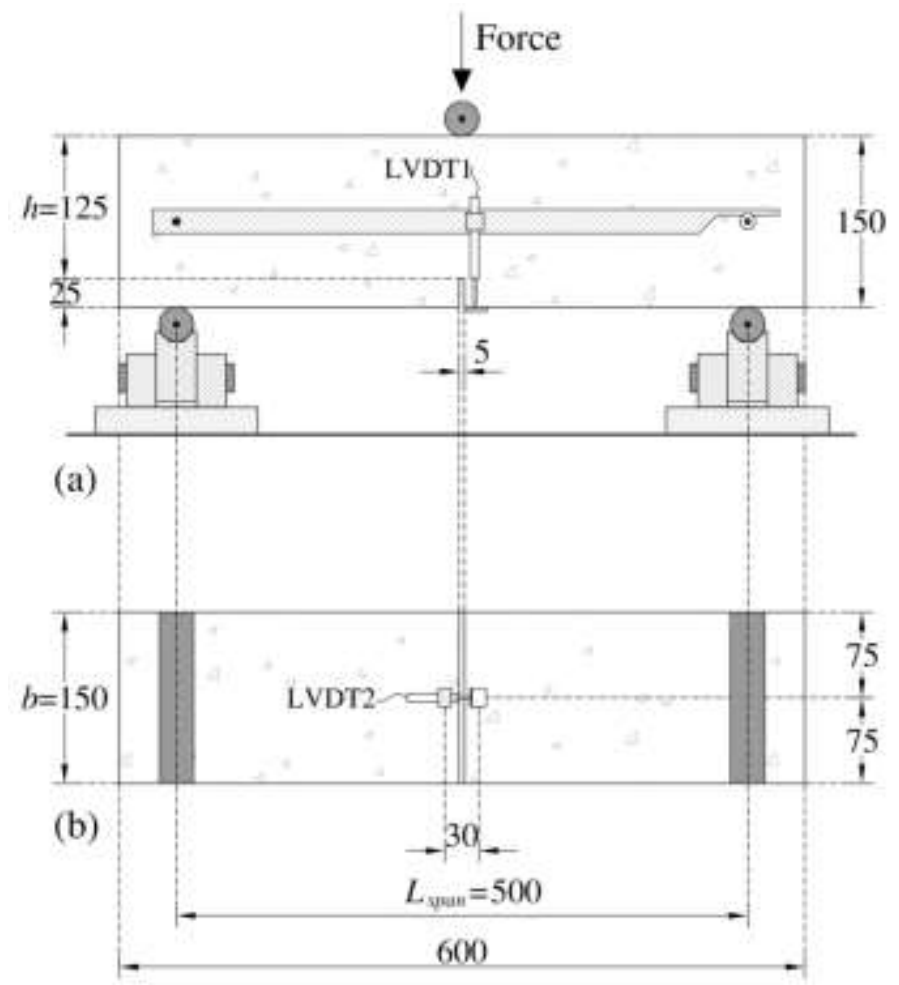

Fig. 6: Three-point notched beam bending test (TBT) setup (dimensions in mm) 


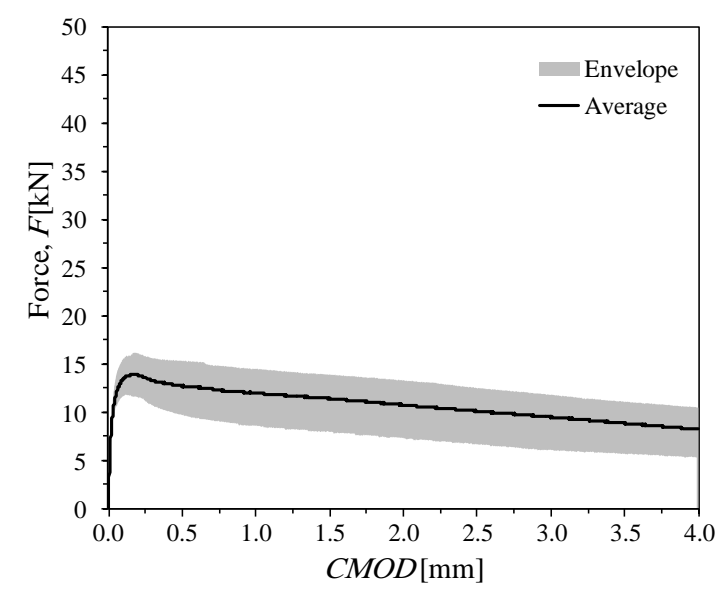

(a)

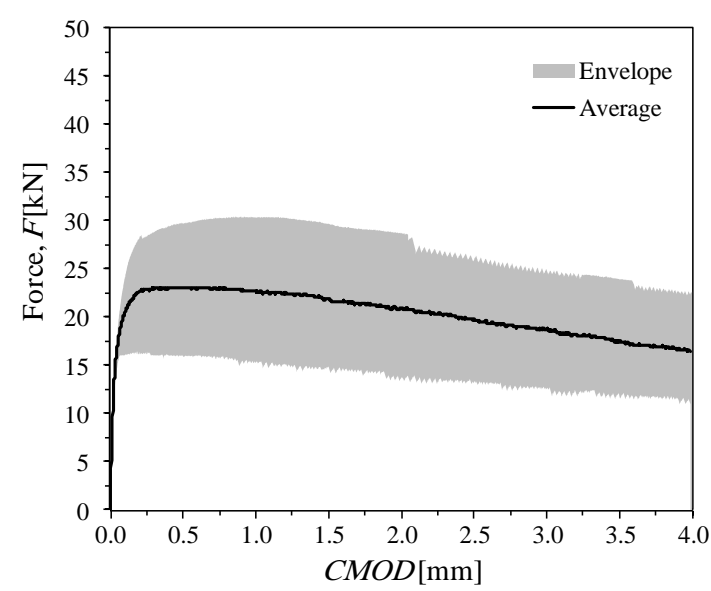

(c)

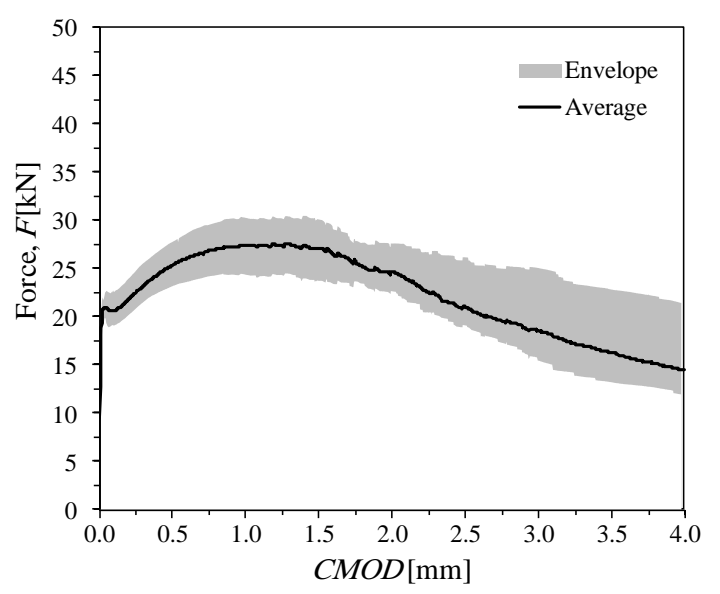

(b)

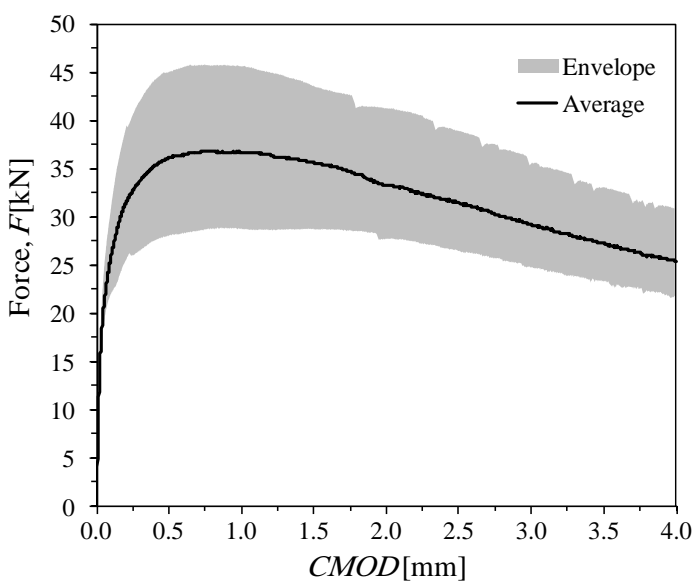

(d)

Fig. 7: Force-CMOD relationships of the four series of specimens of threepoint bending tests: (a) C15-f45, (b) C30-f45, (c) C25-f60, and (d) C45-f90

The envelope and average force-crack mouth opening displacement (F-CMOD) relationships obtained by the performed TBT are depicted in Fig. 7, from which the average flexural residual strength $\left(f_{R i, m}\right)$ is determined by the following equation:

$$
f_{R i, m}=\frac{3 F_{i, m} L_{s p a n}}{2 b h_{s p}^{2}}
$$

where $F_{i, m}$ is the average force corresponding to $\mathrm{CMOD}_{i}$ equal to $0.5,1.5,2.5$, and 3.5 $\mathrm{mm}$. The average values of the flexural residual strengths are summarised in Table 3. 
Table 3: The average values of flexural residual strengths of the SFRCs

\begin{tabular}{ccccc}
\hline SFRC series & $\begin{array}{c}f_{R 1, m} \\
{[\mathrm{MPa}]}\end{array}$ & $\begin{array}{c}f_{R 2, m} \\
{[\mathrm{MPa}]}\end{array}$ & $\begin{array}{c}f_{R 3, m} \\
{[\mathrm{MPa}]}\end{array}$ & $\begin{array}{c}f_{R 4, m} \\
{[\mathrm{MPa}]}\end{array}$ \\
\hline C15-f 45 & 4.02 & 3.62 & 3.20 & 2.80 \\
C30-f 45 & 8.11 & 8.67 & 6.74 & 5.22 \\
C25-f 60 & 7.36 & 7.10 & 6.44 & 5.65 \\
$\mathrm{C} 45-f 90$ & 11.59 & 11.15 & 9.70 & 8.47 \\
\hline
\end{tabular}

The influence of the concrete strength class is quite visible by comparing the results of series C15-f45 and C30-f45. Since a significant increase was obtained for the $f_{R i, m}$ with the increase of $f_{c m}$. The same conclusion can be retrieved by comparing the results from C30-f45 C25-f60 since in spite of the largest content of fibres of this last SFRC, its smallest compressive strength has prevailed in terms of the post-cracking performance of the SFRC.

The linear stress-crack opening displacement of Fig. 8 is recommended by fib Model Code 2010 [35] to represent the post-cracking response of strain softening FRCs [36, 37] in the evaluation of the behaviour of FRC structures.

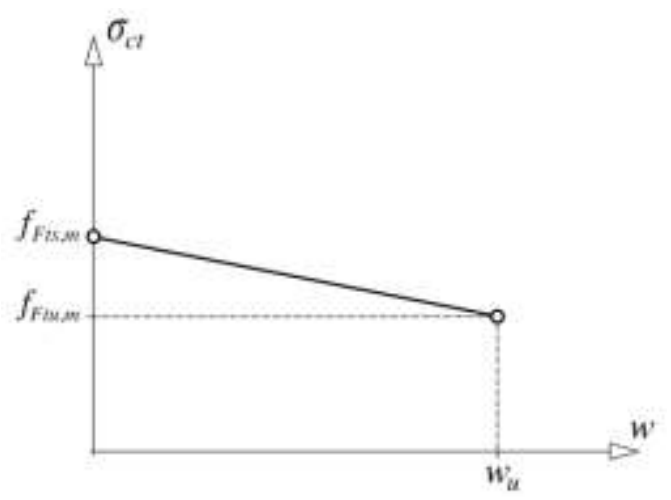

Fig. 8: Stress-crack opening relationship of FRC recommended in fib Model Code 2010 [35]

In Fig. 8, $f_{F t s, m}$ and $f_{F t u, m}$ are the average value of the residual strength of FRC in the serviceability and ultimate limit states, respectively, that can be determined from the following equations [35]: 


$$
\begin{aligned}
& f_{F t s, m}=0.45 f_{R 1, m} \\
& f_{F t u, m}=f_{F t s, m}-\frac{w_{u}}{C M O D_{3}}\left(f_{F t s, m}-0.5 f_{R 3, m}+0.2 f_{R 1, m}\right) \geq 0
\end{aligned}
$$

where $w_{u}$ is the ultimate value of crack opening that depends on the level of required ductility for the FRC element. For design conditions at ultimate limit state (ULS), $w_{u}$ can be considered equal to $2.5 \mathrm{~mm}$. By adopting this methodology, the post-cracking response of the developed SFRCs was characterised as represented in Fig. 9.

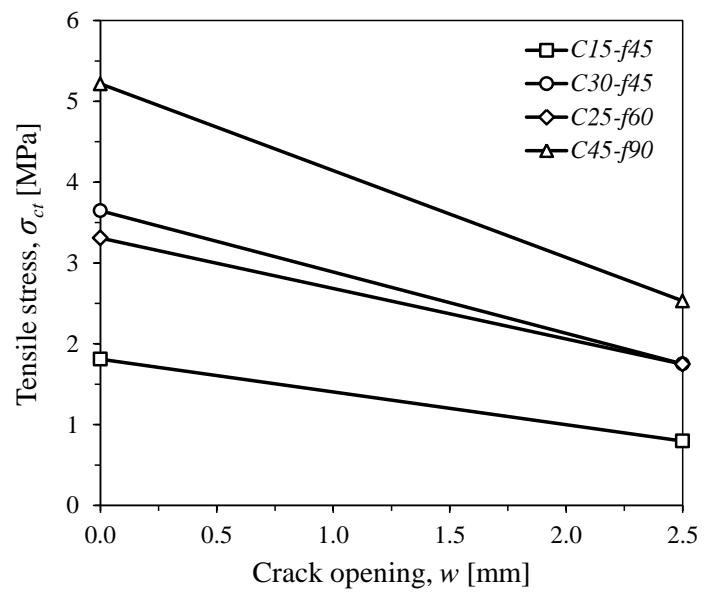

Fig. 9: Post-cracking stress-crack width relationship of the SFRCs determined by following the recommendations of fib Model Code 2010 [35]

When TBT was fulfilled, the total number of visible fibres $\left(N_{f}\right)$ were counted on the nominal fracture surface of $125 \times 150 \mathrm{~mm}^{2}$ of tested beams (Fig. 6) through a visual inspection. Fig. 10 depicts the correlation between the total number of fibres counted on the fracture surface, and the normalised average flexural residual strength of the four series of SFRC corresponding to the a CMOD of $0.5 \mathrm{~mm}$ and $1.5 \mathrm{~mm}\left(f_{R 1, m}\right.$ and $f_{R 3, m}$, respectively). According to Fig. 10, the normalised flexural residual strengths have a tendency to increase linearly with the number of fibres. 

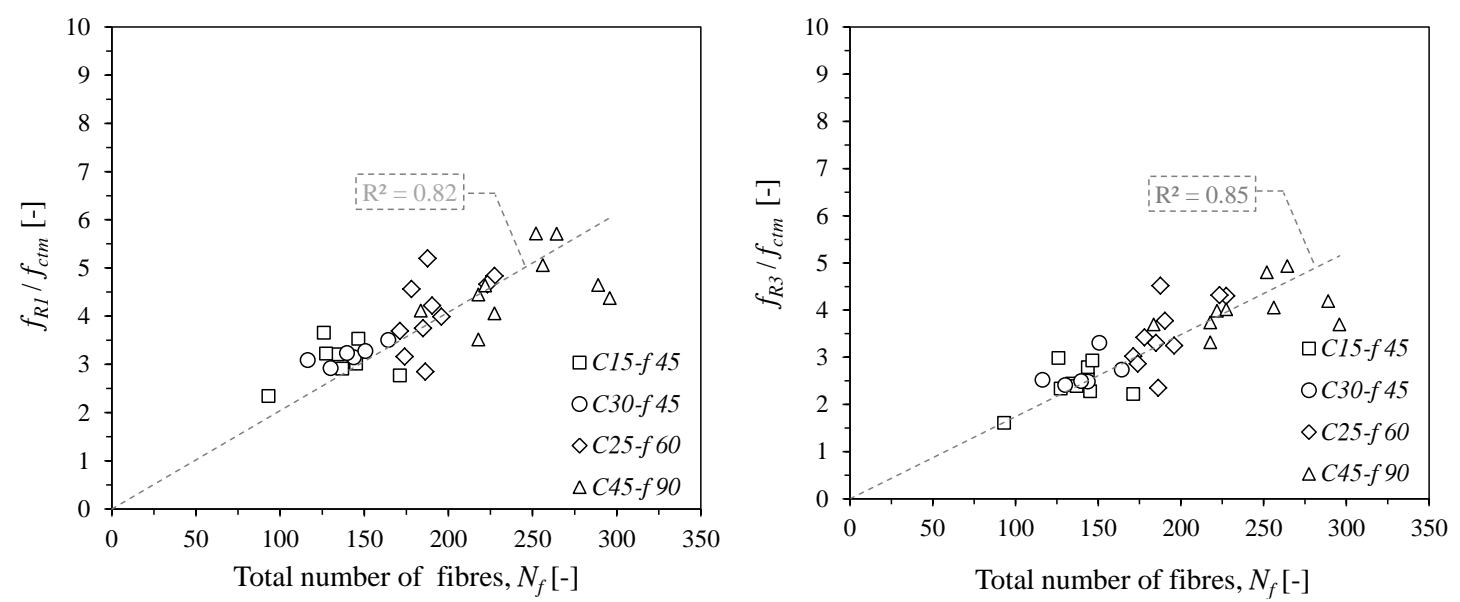

Fig. 10: Influence of the total number of fibres counted on fracture surface on the normalised flexural residual strength at CMOD of (a) $0.5 \mathrm{~mm}\left(f_{R 1, m} / f_{c t m}\right)$ and (b) 1.5 $\mathrm{mm}\left(f_{R 3, m} / f_{c t m}\right)$

By linear regression of the results represented in Fig. 10, the flexural residual strengths of a generic $i^{\text {th }}$ layer of Fig. 5 with a width of $b$ and a height of $\Delta h$ crossed by a $N_{f}^{i}$ can be obtained by the following equations:

$$
\begin{aligned}
& f_{R 1, m}^{i}=0.0204 N_{f}^{i}\left(\frac{125 \times 150}{b \times \Delta h}\right) f_{c t m} \quad\left(f_{R 1 m}^{i} \text { in MPa, } b \text { and } \Delta h \text { in mm }\right) \\
& f_{R 3, m}^{i}=0.0174 N_{f}^{i}\left(\frac{125 \times 150}{b \times \Delta h}\right) f_{c t m} \quad\left(f_{R 3 m}^{i} \text { in MPa, } b \text { and } \Delta h \text { in } \mathrm{mm}\right)
\end{aligned}
$$

Note that the constitutive law of SFRC recommended by the fib Model Code 2010 [35] is dependent on the nominal geometry of the fracture surface of the three-point notched beam bending test. Therefore, in Eqs. (27) and (28) the total number of fibres determined for the cross section of $b \times \Delta h$ is transformed into a $125 \times 150 \mathrm{~mm}^{2}$ surface, which is the area of fracture plane above the notch's apex in the standard three-point notched beam bending test.

It is also noted that Eqs. (27) and (28) were obtained for the SFRCs reinforced with hooked end steel fibres of $35 \mathrm{~mm}$ length with an aspect ratio of 63 (Table 1). Therefore, for other types of fibre these equations need to be updated, but the methodology can be the same proposed in the present work. By following this methodology, the constitutive laws of the layers of the cross section of Fig. 5 can be obtained regarding the number of fibres counted on each layer $\left(N_{f}^{i}\right)$ through the algorithm depicted in Fig. 11. 


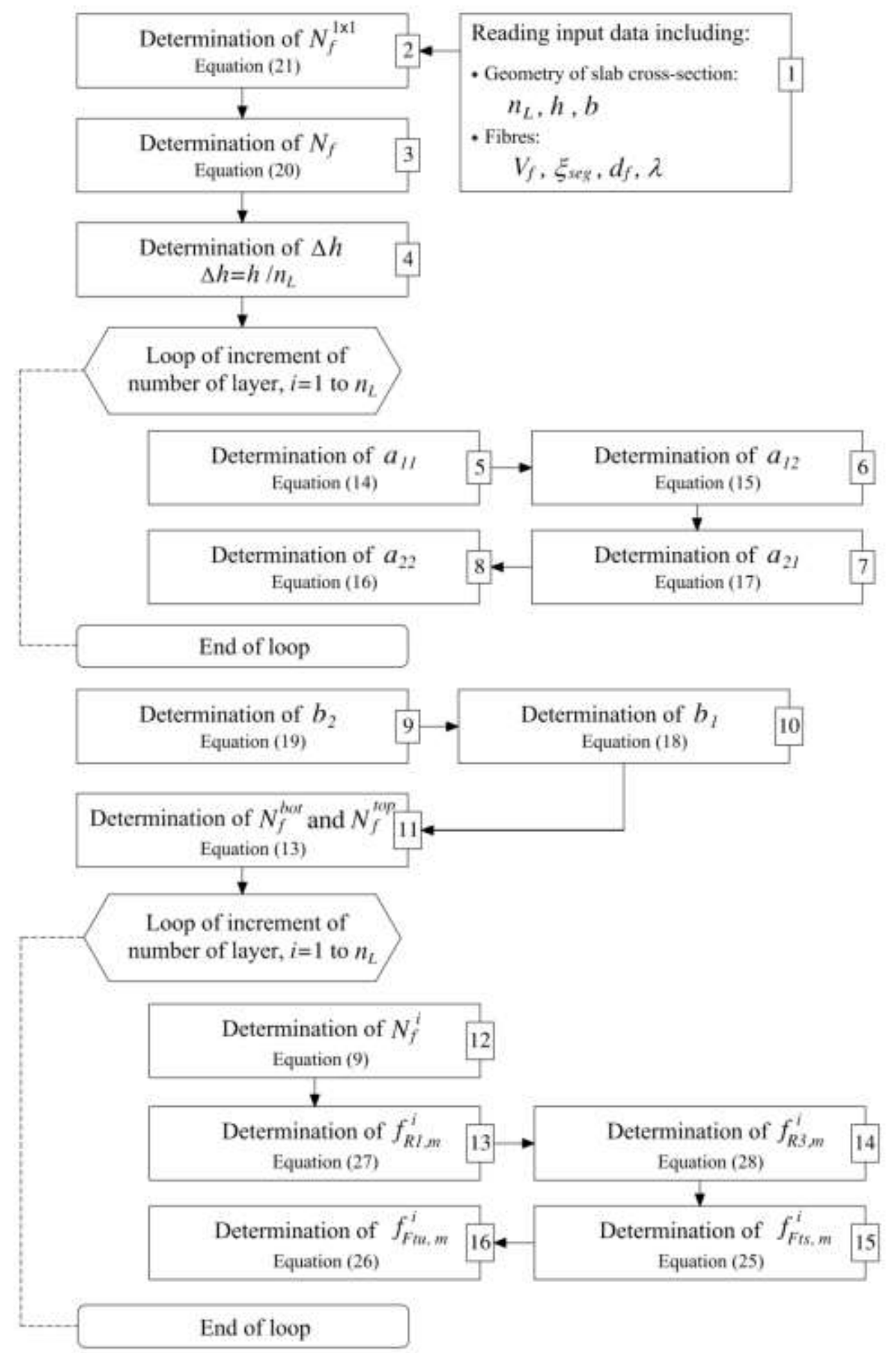

Fig. 11: Algorithm to determine the post-cracking constitutive laws of the $i^{\text {th }}$ layer of cross section 


\section{Prediction of the plastic moment of SFRC slab}

The constitutive laws determined for the layers of the slab's cross section are adopted in the model developed for prediction of the positive and negative plastic moments of the slab's unit width cross section ( $M_{P}^{+}$and $M_{P}^{-}$, respectively). In the developed model, the nonlinear response of a cracked region of a SFRC element is represented by a nonlinear hinge with a length of $L_{h}$ considered around the localised crack. By following the recommendation of fib Model Code 2010 [35], when an element of FRC does not include conventional reinforcement, $L_{h}$ can be assumed equal to the height of its cross section. A layered model, capable of considering all the main mechanisms of a cracked FRC, was developed to predict the moment-rotation response of a nonlinear hinge [38]. In Fig. 12(a) the nonlinear hinge is depicted under pure bending moment $(M)$ that imposes an overall rotation $(\theta)$ on its boundary cross sections. The nonlinear hinge is assumed to have a width varying along its depth symmetrically with respect to the section vertical axis, as depicted in Fig. 12(b).

The height of the beam's cross section is discretized into $n_{L}$ layers. Each layer can have an individual material property in compression and tension. The width, the thickness, and the depth of the generic $i^{\text {th }}$ layer (with respect to the top surface of the section) is designated, respectively, by $b_{i}, t_{i}$, and $d_{i}$ (Fig. 12b).

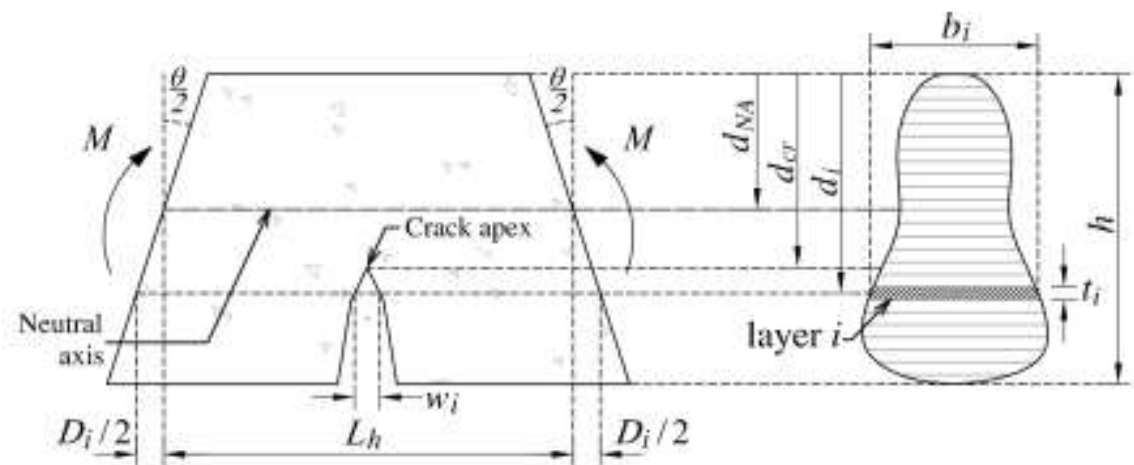

(a)

(b)

Fig. 12: Nonlinear hinge under pure bending; (a) schematic deformational configuration, and (b) layered section 


\subsection{Constitutive laws of FRC assigned to the nonlinear hinge}

\section{Compressive behaviour}

The compressive behaviour of FRC adopted in the model is the stress-strain relationship $\left(\sigma_{c c}-\varepsilon_{c c}\right)$ schematically represented in Fig. 13. This is a representation of the model proposed by Vipulanandan and Paul [39] modified later, by Barros and Figueiras [40] for concrete reinforced with hooked end steel fibres.

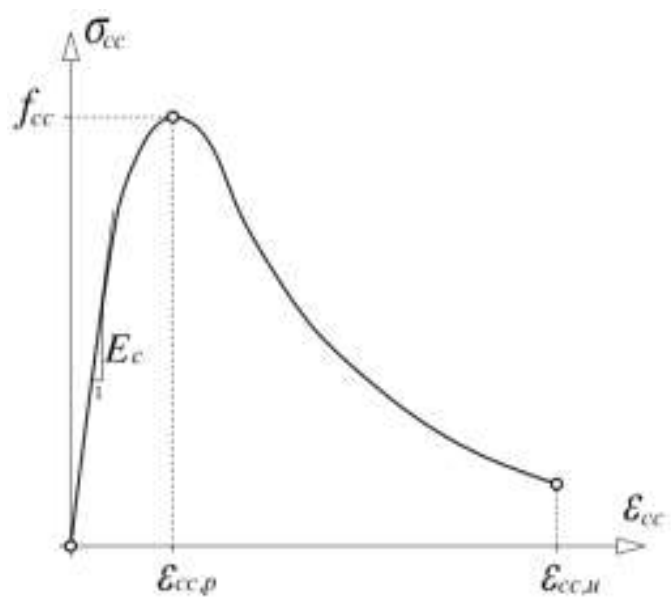

Fig. 13: Typical compressive behaviour of fibre reinforced concrete

It is noted that beyond the peak point, the coalescence of internal microcracks into macro-cracks determines the damage and strain localisation, converting the fracture of concrete into a localised phenomenon. This invalidates the use of strain as a state variable in constitutive laws for compressive concrete [41]. The post-peak behaviour of FRC in compression can be analysed by wedge sliding mechanism [38]. Nevertheless, due to the lack of longitudinal tensile reinforcement in the E-SFRC slab systems considered in the present work, the tensile crack localisation is the dominant failure mode of the FRC elements. Consequently, the post-peak behaviour of FRC in compression is of minor importance to the overall response of the FRC element. Therefore, for the sake of simplicity, in the present approach FRC in post-peak compression stage is still considered a continuous material, and the approach proposed by Barros and Figueiras [40] was adopted: 


$$
\sigma_{c c}\left(\varepsilon_{c c}\right)=f_{c c} \frac{\varepsilon_{c c} / \varepsilon_{c c, p}}{(1-p-q)+q\left(\varepsilon_{c c} / \varepsilon_{c c, p}\right)+p\left(\varepsilon_{c c} / \varepsilon_{c c, p}\right)^{\frac{1-q}{p}}}
$$

where $\varepsilon_{c c, p}$ is the strain corresponding to the concrete compressive strength $\left(f_{c c}\right)$ obtained by the equation below:

$$
\varepsilon_{c c, p}=\varepsilon_{c c, p}^{P C}+0.0002 W_{f}
$$

where $W_{f}$ is the weight percentage of the used fibres, and $\varepsilon_{c c, p}^{P C}$ is the strain at the compressive strength of the plain concrete of the same strength class [35]. In Eq. (29) $E_{c, \text { sec }}$ is the secant modulus of elasticity of concrete $\left(=f_{c c} / \varepsilon_{c c}\right)$, and $E_{c}$ is the concrete elastic modulus determined by Eq. (23). In Eq. (29), $p$ and $q$ are also an empirical coefficient that can be obtained from the following equations:

$$
\begin{aligned}
& p=1.0-0.919 \exp \left(-0.394 W_{f}\right) \\
& \left.q=1-p-\frac{E_{c, \mathrm{sec}}}{E_{c}}, p+q \in\right] 0,1\left[, \frac{1-q}{p}>0\right.
\end{aligned}
$$

In the case that hooked ends steel fibres are not the reinforcement system, Eq. (30) and (32) should be calibrated.

\section{Tensile behaviour}

The tensile behaviour of FRC can be decomposed in the pre-peak and the post-peak stages represented in Figs. 14(a) and (b), respectively.

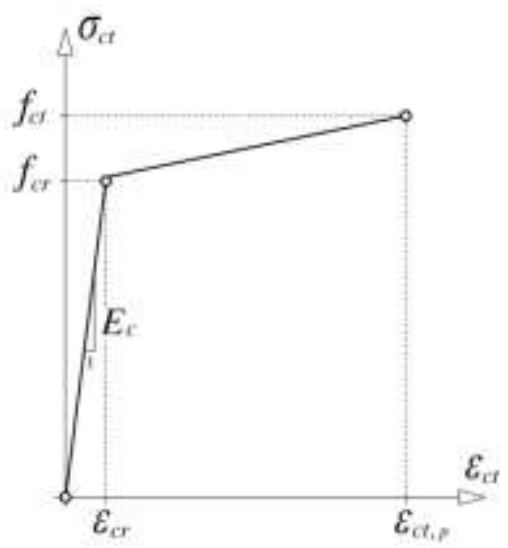

(a)

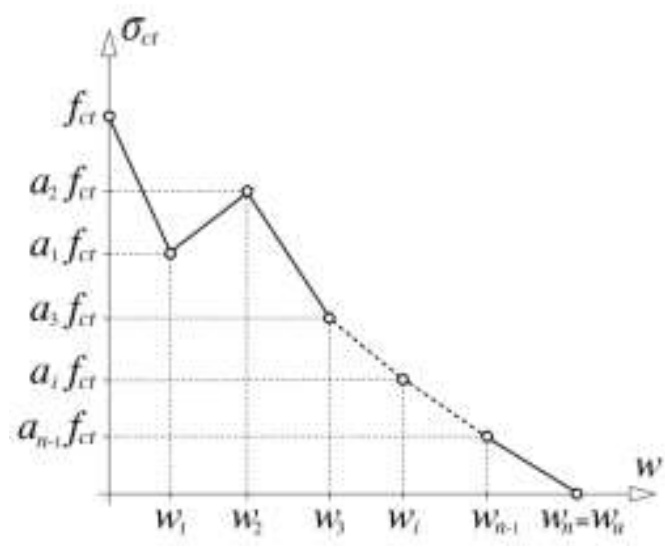

(b) 
Fig. 14: Tensile behaviour of FRC; (a) pre-peak stress-strain relationship, (b) multilinear post-peak stress-crack width relationship

The pre-cracking response of FRC is represented by a bilinear stress-strain relationship determined by the following equation:

$$
\sigma_{c t}\left(\varepsilon_{c t}\right)= \begin{cases}E_{c} \varepsilon_{c t} & \left(0 \leq \varepsilon_{c t} \leq \varepsilon_{c r}\right) \\ \left(\varepsilon_{c t}-\varepsilon_{c r}\right)\left(f_{c t}-f_{c r}\right) /\left(\varepsilon_{c t, p}-\varepsilon_{c r}\right)+\sigma_{c r} & \left(\varepsilon_{c r} \leq \varepsilon_{c t} \leq \varepsilon_{c t, p}\right)\end{cases}
$$

where $f_{c r}$ is the cracking strength that is equal to the mean axial tensile strength $\left(f_{c t m}\right)$ of the concrete matrix determined by the Eq. (22). The second ascending branch adopted in Fig. 14(a) is representative of the increase in the post-cracking stress of the strain hardening FRCs [32], whose tensile capacity increases up to the tensile strength ( $\left.f_{c t}\right)$ and corresponding strain $\left(\varepsilon_{c t, p}\right)$. Note that in case of strain softening FRCs, $f_{c t}$ coincides with the cracking strength $\left(f_{c r}\right)$, and the second branch of Fig. 14(a) is eliminated.

Regarding the fictitious crack model proposed by Hillerborg [42], the tensile post-peak response of FRC is represented by a stress-crack width relationship $\left(\sigma_{c t}-w\right)$, like the one schematically represented in Fig. 14(b). A multi-linear $\sigma_{c t}-w$ diagram was adopted since it can capture, with high accuracy, the softening behaviour of FRCs in tension [43]. The stress versus crack width relationship of Fig. 14(b) can be represented by the following equation:

$$
\sigma_{c t}(w)=\left[a_{m}+\left(a_{m+1}-a_{m}\right) \frac{w-w_{m}}{w_{m+1}-w_{m}}\right] f_{c t} \quad\left(w_{m}<w \leq w_{m+1}\right)
$$

where $m$ is a counter ranging between 0 and the number $n$ of the considered postcracking branches. The $a_{m}=\sigma_{c t, m} / f_{c t}$ is the normalised stress parameter corresponding to the crack width $w_{m}$. Furthermore, $\left(a_{0}, w_{0}\right)$ and $\left(a_{n}, w_{n}\right)$ are equal to $(1,0)$ and $\left(0, w_{u}\right)$, respectively, where $w_{u}$ is the ultimate crack width. 


\subsection{Algorithm to predict the moment-rotation response of the nonlinear hinge}

In a developed incremental-iterative algorithm, for a $k^{\text {th }}$ generic step of computation, the overall rotation of the hinge $\left(\theta_{k}\right)$ is increased symmetrically by a constant rate of $\Delta \theta$ :

$$
\theta_{k}=k \Delta \theta
$$

Correspondingly, the axial elongation of the $i^{\text {th }}$ layer $\left(D_{i}^{k}\right)$ is determined regarding the depth of the layer $\left(d_{i}\right)$ and the considered depth of the neutral axis $\left(d_{N A}\right)$ :

$$
D_{i}^{k}=\theta_{k}\left(d_{i}-d_{N A}\right)
$$

The effective strain in the $i^{\text {th }}$ layer is then determined from the following equation:

$$
\varepsilon_{e f, i}^{k}=\frac{D_{i}^{k}}{L_{h}}
$$

For the layers positioned above the neutral axis, $\left(d_{i} \leq d_{N A}\right)$, the compressive force $\left(F_{c c, i}^{k}\right)$ is obtained from equation below:

$$
F_{c c, i}^{k}=\sigma_{c c}\left(\varepsilon_{e f, i}^{k}\right) b_{i} t_{i}
$$

where $\sigma_{c c}\left(\varepsilon_{e f, i}^{k}\right)$ is determined by Eq. (29). The tensile force $\left(F_{c t, i}^{k}\right)$ of the layers below the neutral axis, $\left(d_{i}>d_{N A}\right)$ is determined by the following equation:

$$
F_{c t, i}^{k}= \begin{cases}\sigma_{c t}\left(\varepsilon_{e f, i}^{k}\right) b_{i} t_{i} & \left(\varepsilon_{e f, i}^{k} \leq \varepsilon_{c t, p}\right) \\ \sigma_{c t}\left(w_{i}^{k}\right) b_{i} t_{i} & \left(\varepsilon_{e f, i}^{k}>\varepsilon_{c t, p}\right)\end{cases}
$$

where $\sigma_{c t}\left(w_{i}^{k}\right)$ is obtained by solving iteratively Eq. (40):

$$
D_{i}^{k}+\left[\frac{f_{c t}-\sigma_{c t}\left(w_{i}^{k}\right)}{E_{c}}-\varepsilon_{c t, p}\right] L_{h}-w_{i}^{k}=0
$$

To deduce Eq. (40) it is assumed that when the crack crosses the $i^{\text {th }}$ layer, the total elongation of the layer $\left(D_{i}^{k}\right)$ is a superimposition of the widening of the crack $\left(w_{i}^{k}\right)$ 
and the elastic deformation of the layer $\left(\varepsilon_{c t, p}-\left(f_{c t}-\sigma_{c t}\left(w_{i}^{k}\right)\right) / E_{c}\right)$ along the hinge, as described in Fig. 15.

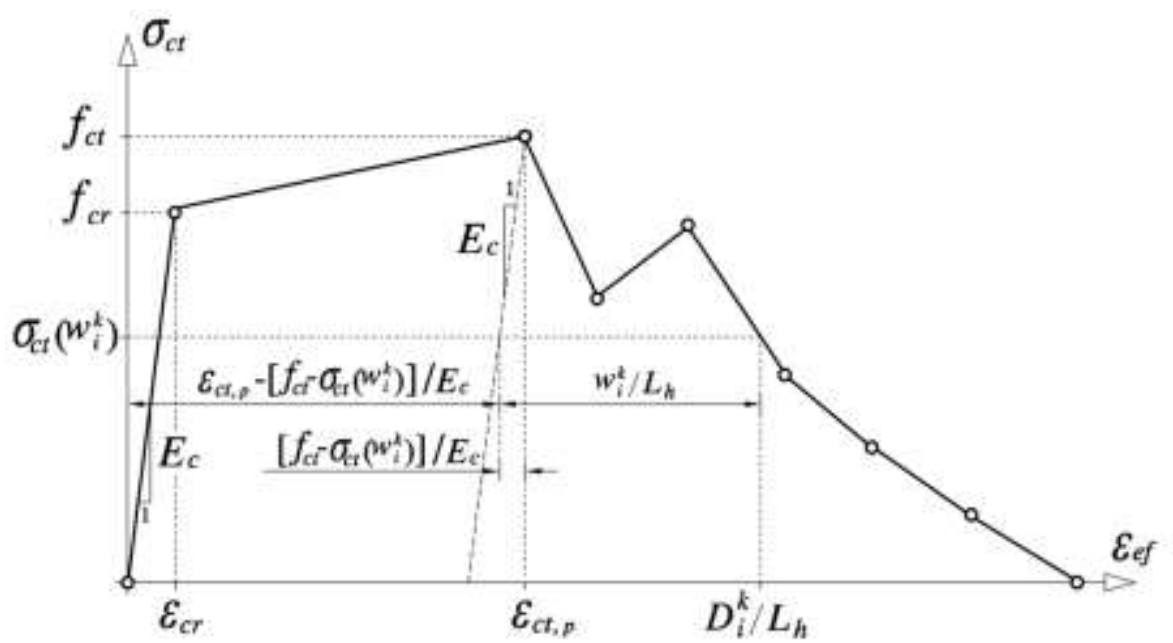

Fig. 15: The components of the effective strain of the $i^{\text {th }}$ layer in tension

By imposing the equilibrium of the axial forces determined for the layers over the height of the cross section, the depth of the neutral axis $\left(d_{N A}\right)$ is determined for the overall rotation $\left(\theta_{k}\right)$ applied to the nonlinear hinge. For this equilibrium configuration, the bending moment is determined:

$$
M_{k}=\sum_{i=1}^{n_{L}} F_{i} d_{i}
$$

where $n_{L}$ is the number of layers of the cross section. The explained procedure is described in the flowchart of Fig. 16, which defines a point of the moment-rotation relationship $\left(M_{k}-\theta_{k}\right)$.

The positive plastic moment $\left(M_{P}^{+}\right)$of the slab's cross section is considered as the maximum value of the bending moment in the determined $M-\theta$ relationship. The proposed computational procedure can also be used for determining the negative plastic moment $\left(M_{P}^{-}\right)$by reversing the order of the layers' enumeration. The determined positive and negative plastic moment of the slab's cross section can then be substituted in Eq. (1) to (4), developed based on the yield line theory, for determining the load carrying capacity of the interior and corner panels of E-SFRC slab under uniformly distributed and quasi-point loads. 


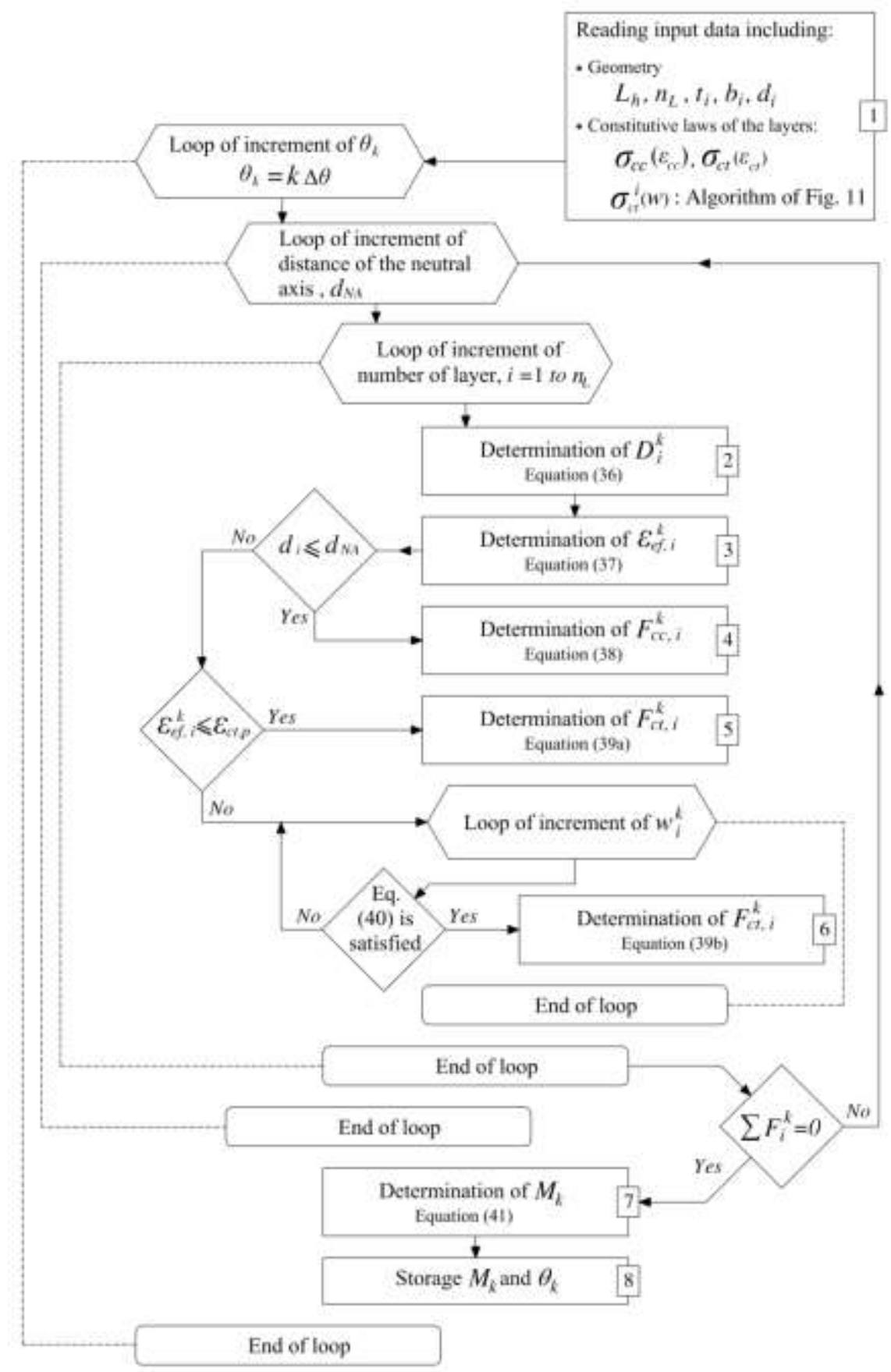

Fig. 16: Flowchart of the algorithm of the model developed for determining the moment-rotation response of FRC nonlinear hinge

\section{Assessment of predictive performance of the developed model}

The predictive performance of the developed model is evaluated by comparing to the test results registered in the experimental programme conducted on an E-SFRC slab of a quarter-scale prototype made entirely by a concrete of $65 \mathrm{MPa}$ compressive strength and reinforced with $1.1 \%$ of volume fraction of hooked end steel fibres. The test 
program is explained in detail elsewhere [2]. The prototype was made of six $1.2 \times 1.0 \mathrm{~m}$ panels supported on 12 columns of $100 \times 100 \mathrm{~mm}^{2}$ cross section. The load carrying capacity of a $1.2 \times 1.0 \mathrm{~m}$ corner panel was evaluated under quasi-point load applied on a $200 \times 200 \mathrm{~mm}^{2}$ area at the panel centre. The thickness of the panel was $75 \mathrm{~mm}$. The ultimate crack pattern of the loaded panel is depicted in Fig. 17(a) and is idealised in Fig. 17(b) where the equivalent circular yield line of the negative plastic moment with a radius $(R)$ of $618.1 \mathrm{~mm}$ diameter was determined by Eq. 5. Furthermore, the centrally loaded area was transformed into an equivalent circular area of radius $(r)$ equal to $112.9 \mathrm{~mm}$.

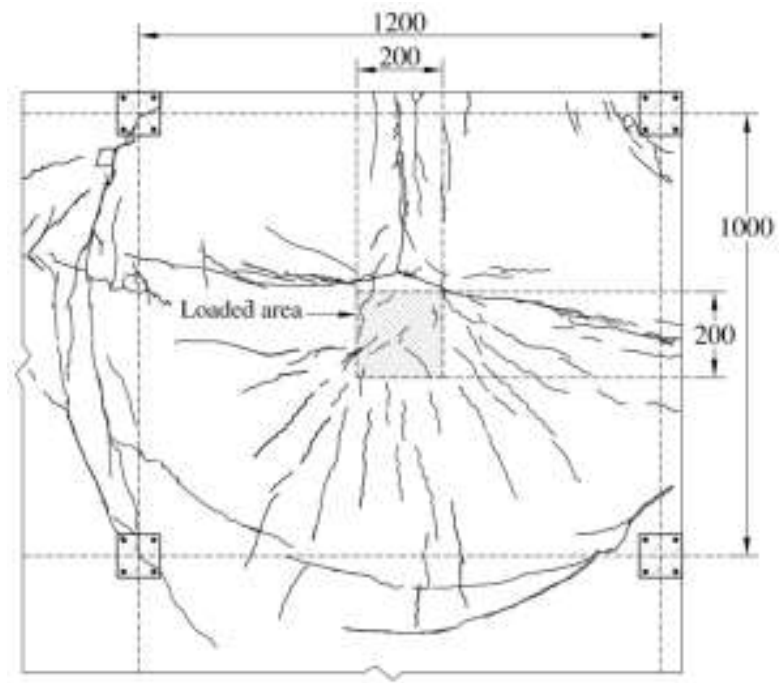

(a)

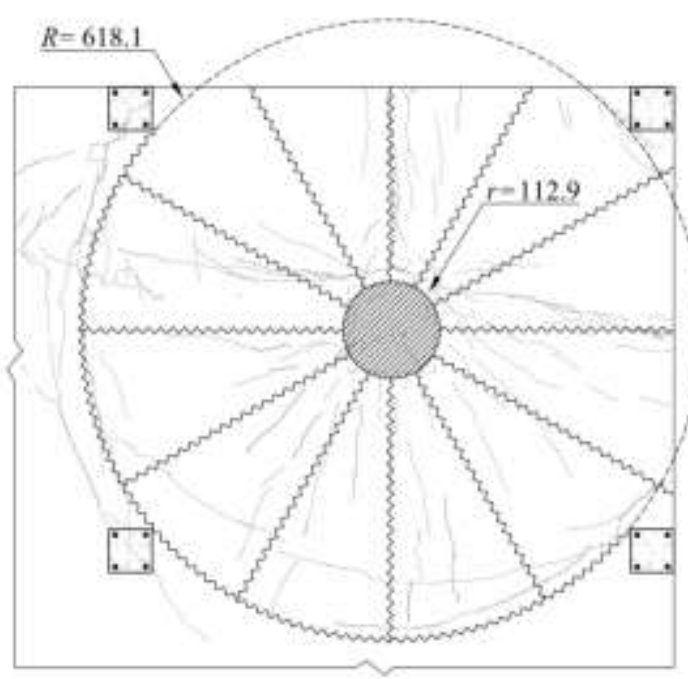

(b)

Fig. 17: (a) Ultimate crack pattern of the tested elevated SFRC slab under concentric load [2] and (b) idealised ultimate crack pattern (dimensions in mm)

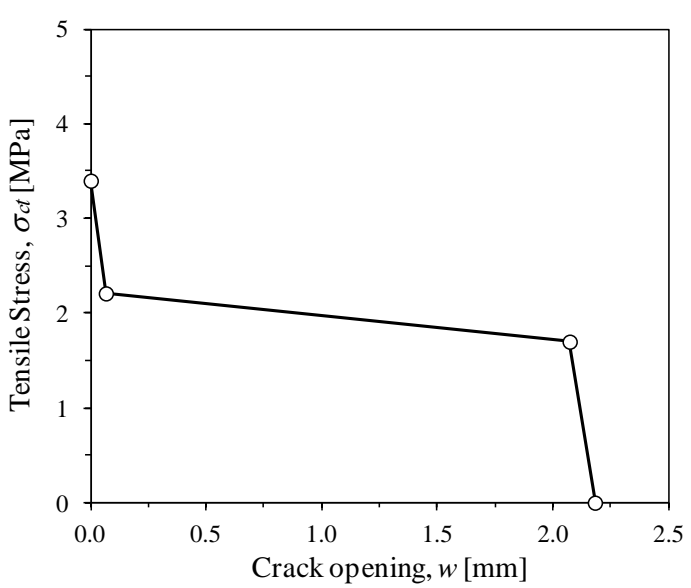

(a)

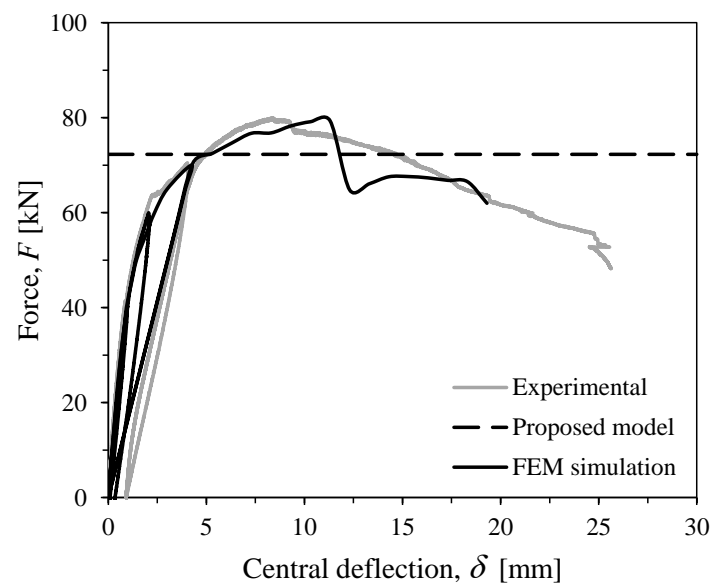

(b) 
Fig. 18: (a) Stress-crack width relationship obtained by the inverse analysis of the test conducted on the E-SFRC slab prototype and (b) predictive performance of the proposed model compared to the test results

The average post-cracking response of Fig. 18(a) is assigned to the layers of the slab's cross section. This stress-crack width diagram was obtained by inverse analysis by fitting with the minimum error as possible the force-central deflection registered experimentally in the tested prototype (Fig. 18b) as described in detail elsewhere [2]. In the performed inverse analysis the test was simulated by finite element method (FEM) based on a smeared crack model implemented in FEMIX V4.0 software [44] that is described in details elsewhere [45]. The finite element mesh of Fig. 19 was adopted, where the E-SFRC slab's thickness was discretized in 20 layers of eight nodes finite elements according to the Mindlin-shell theory with Gauss-Legendre (G-L) integration scheme of $2 \times 2$ Integration Points (IP). The same type of finite elements was also used to simulate the foundations. The columns were simulated by solid elements of 20 nodes with $2 \times 2 \times 2$ G-L IP, while T cross arrangements of three dimensional (3D) Timoshenko beam elements were utilised with $1 \times 3$ IP with a relative large flexural stiffness to assure rotational compatibility between the shell and solid elements in the ESFRC slab/column connections (Fig. 19).

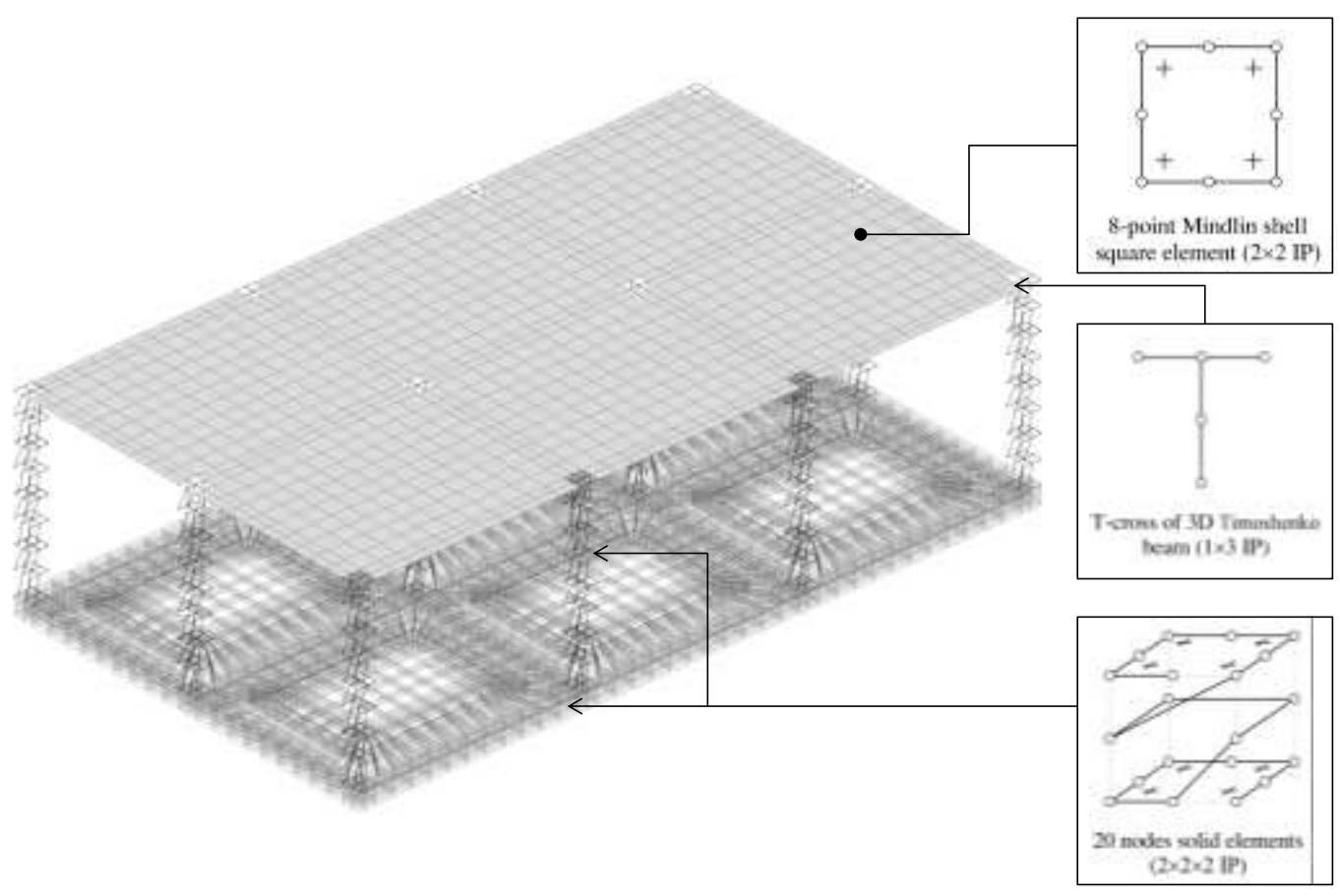

Fig. 19: Finite element mesh of the prototype 
In the material nonlinear analysis with smeared crack constitutive models implemented under the framework of FEM, the stress-crack width was converted to a stress-strain diagram, which simulates the fracture mode I propagation, by using of the concept of crack bandwidth $\left(l_{b}\right)[46]$ :

$$
\varepsilon_{n n}^{c r}=w / l_{b}
$$

where $\varepsilon_{n n}^{c r}$ is the strain normal to the smeared cracks and $l_{b}$ is assumed equal to the square root of the area of the corresponding integration point to ensure results independent of the mesh refinement [47].

By assuming a unitary value for $\varphi_{h}$ parameter, the load carrying capacity of the E-SFRC slab was determined by the proposed model as indicated by the dashed line in Fig. 18(b) according to which prediction of the model is desirably $8 \%$ lower than the average peak load recorded in the experiment. The developed FEM based model was also used to assess the reliability of the proposed model for a case study, where a square E-SFRC panel of $6300 \mathrm{~mm}$ edge and a thickness of $200 \mathrm{~mm}$ is supported on four reinforced concrete columns of $3000 \mathrm{~mm}$ height and $300 \times 300 \mathrm{~mm}^{2}$ cross section. The columns are assumed to be supported by four square foundations of $1500 \mathrm{~mm}$ edge and $350 \mathrm{~mm}$ thickness. The geometry of this structure is depicted in Fig. 20.

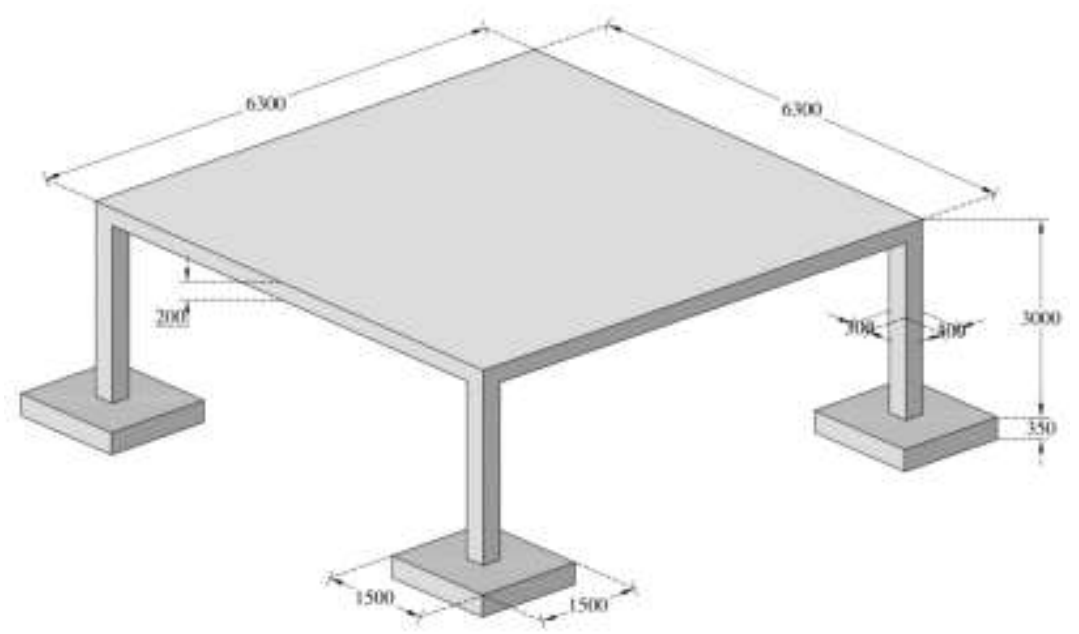

Fig. 20: Geometry of the E-SFRC slab considered for evaluation of the predictive performance of the developed model (dimensions in $\mathrm{mm}$ ) 
The considered slab is made of a concrete of compressive strength of $65 \mathrm{MPa}$, reinforced with $0.8 \%$ of volume fraction $\left(V_{f}\right)$ of hooked end steel fibres of $35 \mathrm{~mm}$ length and an aspect ratio of 63. The segregation degree of fibres along the section's depth $\left(\xi_{\text {seg }}\right)$ and the fibre efficiency factor $(\lambda)$ is assumed 0.6 and $1 / \pi$, respectively. The thickness of the slab's cross section is discretized in 20 layers $\left(n_{L}\right)$ of $10 \mathrm{~mm}$ thickness each $(\Delta h)$. By following the methodology described in the algorithm of Fig. 11, the post-cracking constitutive law of the layers was determined as depicted in Fig. 21(a). Correspondingly, the positive and negative moment-rotation relationships of the unit width of the slab's cross section, shown in Fig. 21(b), were evaluated by applying the algorithm described in the flowchart represented in Fig. 16.

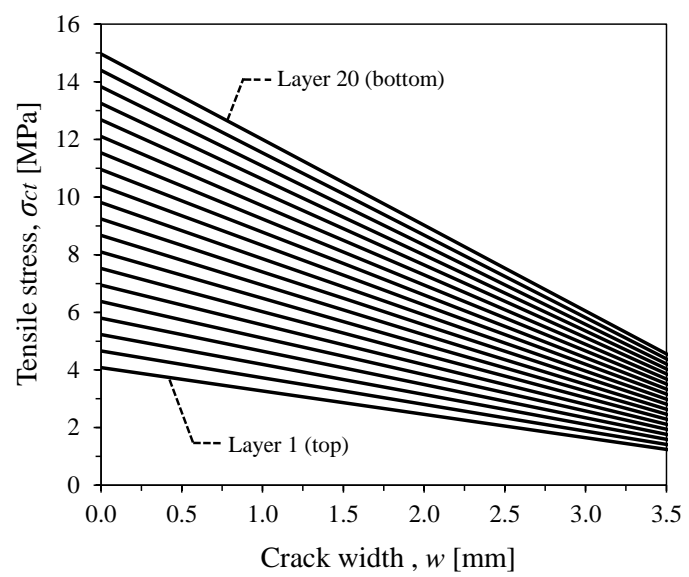

(a)

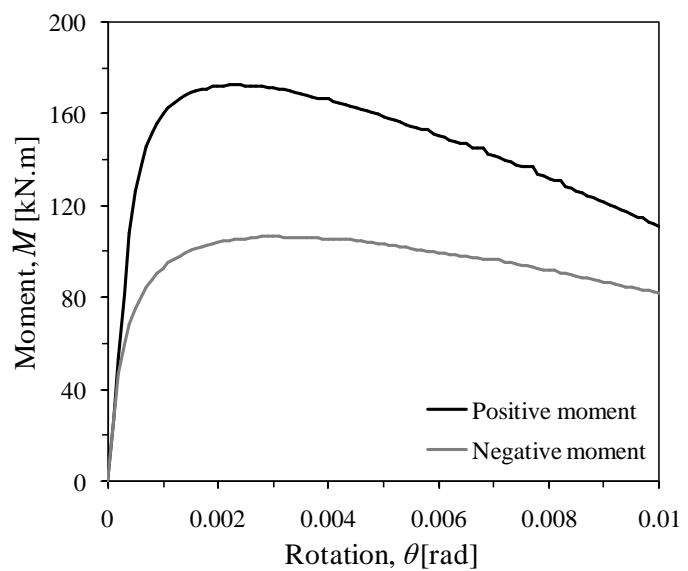

(b)

Fig. 21: (a) Stress-crack width diagram of the layers of the slab's cross section and (b) moment-curvature relationship of the unit width of the E-SFRC slabs

The maximum value of the positive and negative moments-rotation relationship of Fig. 21(b) was considered as the positive and negative plastic moment of the unit width of the slab's cross section $\left(M_{P}^{+}\right.$and $\left.M_{P}^{-}\right)$, respectively. These values are indicated in Table 4. The ultimate uniformly distributed load and quasi-point load supported by an interior and corner panel of the E-SFRC slab, with the same geometry depicted in Fig. 20, were determined by Eq. (1) to (5), respectively. These values are also included in Table 4. Note that a $300 \times 300 \mathrm{~mm}^{2}$ area was considered for the quasi-point load. 
Table 4: Ultimate uniform and quasi-point load of the interior and corner panel

\begin{tabular}{cccccccc}
\hline $\begin{array}{c}M_{P}^{+} \\
{[\mathrm{kN} . \mathrm{m} / \mathrm{m}]}\end{array}$ & $\begin{array}{c}M_{P}^{-} \\
{[\mathrm{kN} . \mathrm{m} / \mathrm{m}]}\end{array}$ & $\begin{array}{c}\varphi_{h} \\
{[-]}\end{array}$ & $\begin{array}{c}L_{r x}=L_{r y} \\
{[\mathrm{~m}]}\end{array}$ & $\begin{array}{c}q_{u l t, \text { int }} \\
{\left[\mathrm{kN} / \mathrm{m}^{2}\right]}\end{array}$ & $\begin{array}{c}q_{\text {ult,cor }} \\
{\left[\mathrm{kN} / \mathrm{m}^{2}\right]}\end{array}$ & $\begin{array}{c}P_{u l t, \text { int }} \\
{[\mathrm{kN}]}\end{array}$ & $\begin{array}{c}P_{\text {ult,cor }} \\
{[\mathrm{kN}]}\end{array}$ \\
\hline 173 & 107 & 0.62 & 5.80 & 62.18 & 49.60 & 1818.80 & 1471.62 \\
\hline
\end{tabular}

By using the concept of crack bandwidth $\left(l_{b}\right)$ [46], the constitutive laws of the layers in terms of stress-crack width relationship (Fig. 21a) were converted to the crack normal stress versus crack normal strain diagram that simulates the mode I fracture of the smeared cracks formed in integration points of the finite element. Furthermore, a linear and elastic behaviour was assigned to the concrete of the columns and foundations. To simulate the behaviour of the interior panel, the rotation of the points located on each border was restrained, while in case of corner panel two perpendicular sides of the panel were kept free to rotate. In Fig. 22 and 23, the load versus central deflection relationship of the panel, determined by the FEM simulation, is compared to the ultimate value of the load predicted by the proposed model for the uniformly distributed and quasi-point load, respectively. When compared to the FEM simulation, the ultimate load predicted by the model has a difference of $11 \%$ and $16 \%$ in case of the interior panel subjected to uniformly distributed and quasi-point load, respectively, while a difference of $2 \%$ and $18.5 \%$ was obtained for the corner panel under uniformly distributed and quasi-point load, respectively, which reveals good prediction of the model.

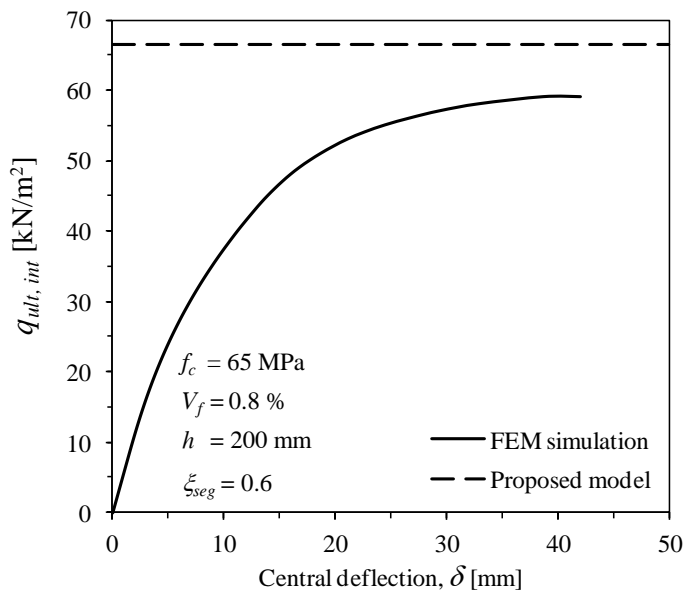

(a)

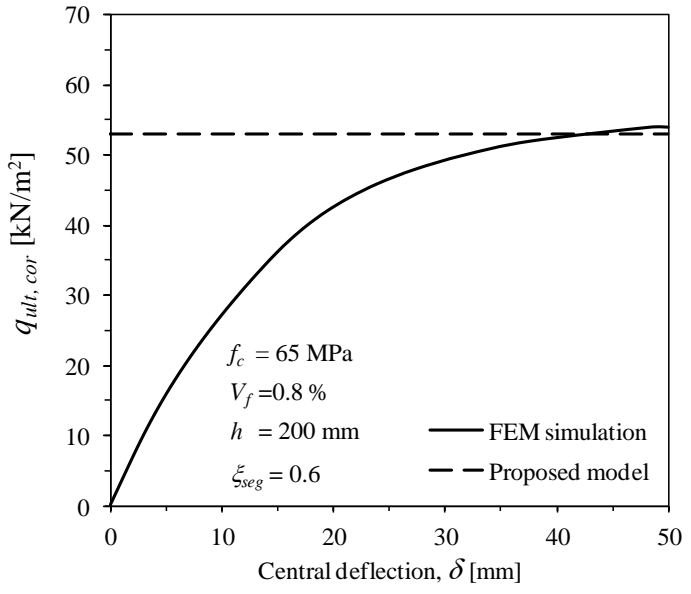

(b) 
Fig. 22: Evaluation of the model prediction by the FEM simulation in case of (a) interior and (b) corner panel under uniformly distributed load

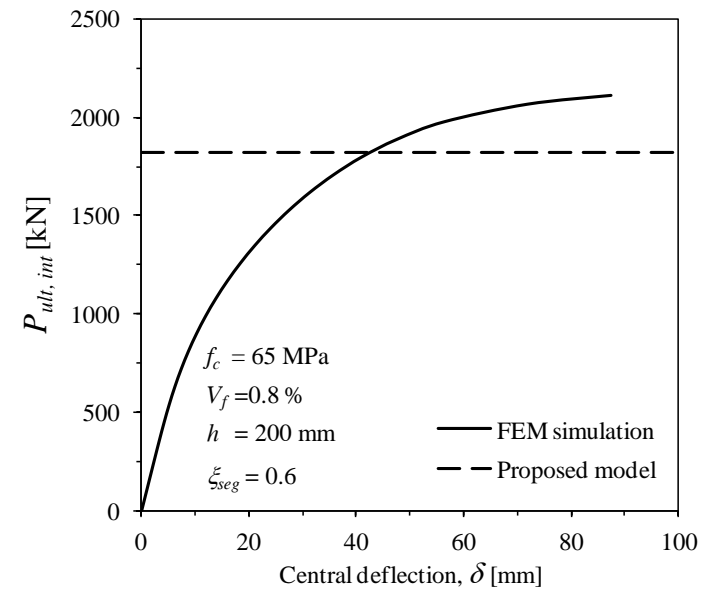

(a)

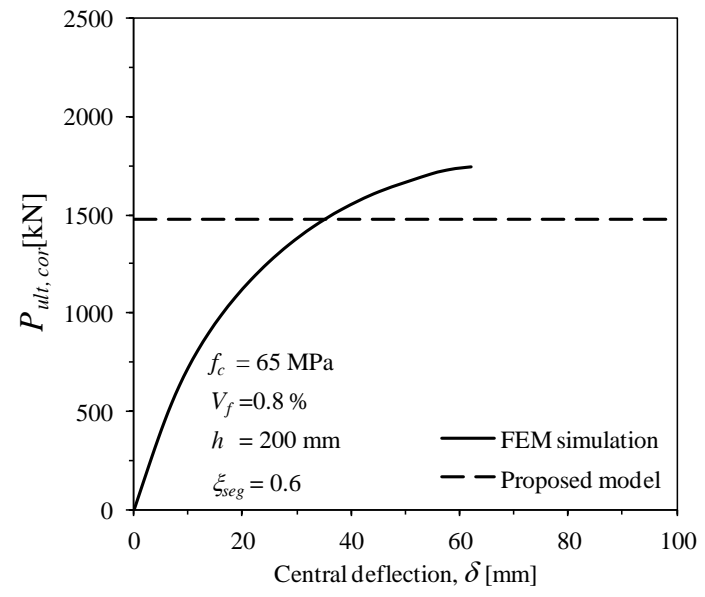

(b)

Fig. 23: Evaluation of the model prediction by the FEM simulation in case of (a) interior and (b) corner panel under quasi-point load

\section{Parametric study on the load-carrying capacity of E-SFRC slabs}

By using the developed model, the influence of parameters that affect the load-carrying capacity of E-SFRC slabs was evaluated by executing a parametric study. The considered parameters and their range of values are summarised in Table 5. For the sake of simplicity, an equal effective span length is assumed for the E-SFRC slab in the $x$ and $y$ directions, and a homogeneous dispersion of fibres is assumed over the slab surface and, consequently, $\varphi_{h x}=\varphi_{h y}=\varphi_{h}$.

Table 5: Range of values for the considered parameters in the parametric study

\begin{tabular}{lll}
\hline Variables & Range of values & Increment of value \\
\hline Height of cross section $(h)$ & {$[150 \mathrm{~mm}-350 \mathrm{~mm}]$} & $50 \mathrm{~mm}$ \\
Effective span length $\left(L_{r x}=L_{r y}\right)$ & {$[2.5 \mathrm{~m}-7 \mathrm{~m}]$} & $0.5 \mathrm{~m}$ \\
Volume fraction of fibres $\left(V_{f}\right)$ & {$[0.6 \%-1.2 \%]$} & $0.1 \%$ \\
Degree of segregation $\left(\xi_{\text {seg }}\right)$ & {$[0.5-1.0]$} & 0.1 \\
Fibre efficiency factor $(\lambda)$ & $1 / \pi$ & - \\
Diameter of fibre cross section $\left(d_{f}\right)$ & $0.50 \mathrm{~mm}$ & -
\end{tabular}




$\begin{array}{lll}\text { Compressive strength of concrete }\left(f_{c}\right) & {[30 \mathrm{MPa}-80 \mathrm{MPa}]} & 10 \mathrm{MPa} \\ \text { Position of panel } & \text { Interior/Corner } & - \\ \text { Load configuration } & \begin{array}{l}\text { Uniform } \\ \text { distributed/Concentric }\end{array} & - \\ r \text { (for quasi-point loading) } & r / h=1.0 & -\end{array}$

\subsection{Influence of the fibres segregation on $\varphi_{h}$ parameter}

In Fig. 24 the influence of the fibres segregation $\left(\xi_{\text {seg }}\right)$ on the negative-to-positive plastic moment ratio $\left(\varphi_{h}=M_{P}^{-} / M_{P}^{+}\right)$is depicted. As expected, when the fibre distribution is uniform along the depth of the slab's cross section $\left(\xi_{\text {seg }}=0.5\right)$, an equal negative and positive plastic moment of the FRC section is determined $\left(\varphi_{h}=1\right)$. The $\varphi_{h}$ parameter, however, reduces with the increase in the fibres segregation degree, regardless of the height of slab's cross section, compressive strength class of concrete, and volume fraction of the fibres.

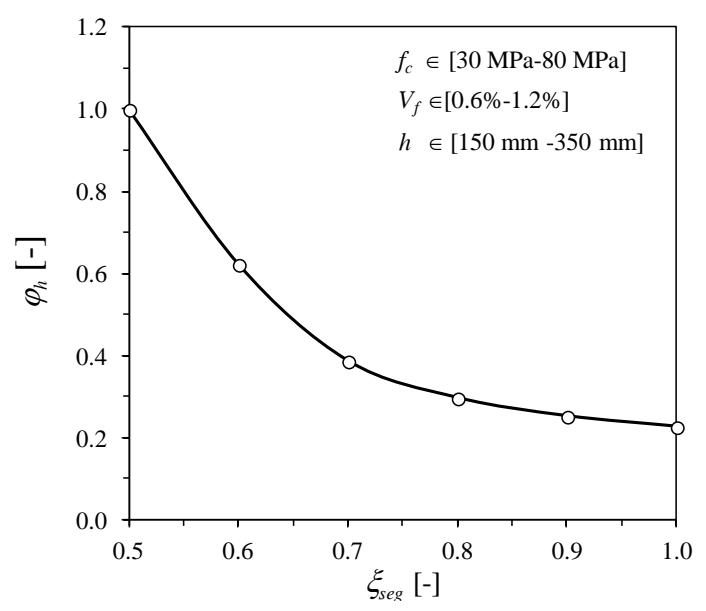

Fig. 24: $\varphi_{h}-\xi_{\text {seg }}$ relationship

According to Fig. 24, the reduction of the $\varphi_{h}$ parameter by the increase of the fibre segregation is more pronounced up to a fibres segregation value of 0.7 , beyond which the $\varphi_{h}-\xi_{\text {seg }}$ curve tends asymptotically to 0.2 . Fig. 25 shows that by increasing the fibres segregation parameter the positive plastic moment of the unit width of slab's cross section increases linearly, while the negative plastic moment decreases almost linearly up to $\xi_{\text {seg }} \approx 0.7$ and then by tends to an asymptotic value. In fact, above this 
fibres segregation limit, the number of fibres in the cracked layers tends to zero, leading to null residual flexural tensile strengths, and, therefore, the negative plastic moment coincides with the moment at cracking initiation.

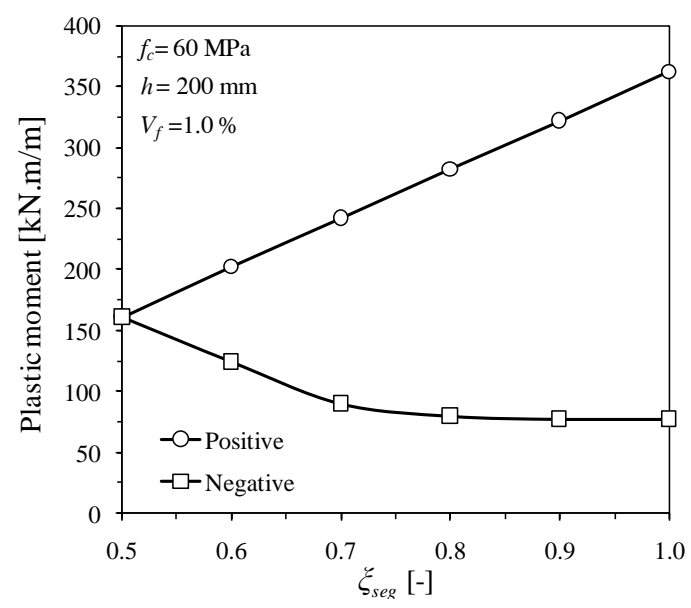

Fig. 25: Influence of the fibres segregation on the positive and negative plastic moment of the slab's unit width cross section

\subsection{Influence of volume percentage of fibres}

The influence of the volume percentage of fibres $\left(V_{f}\right)$ on the ultimate uniformly distributed and the quasi-point load of E-SFRC slab, is depicted in Fig. 26 and 27, respectively. According to these figures an increase of around $80 \%$ in the load carrying capacity of the E-SFRC slab is achieved by increasing the volume of fibres from $0.6 \%$ to $1.2 \%$, for each load configuration and type of the loaded panel.
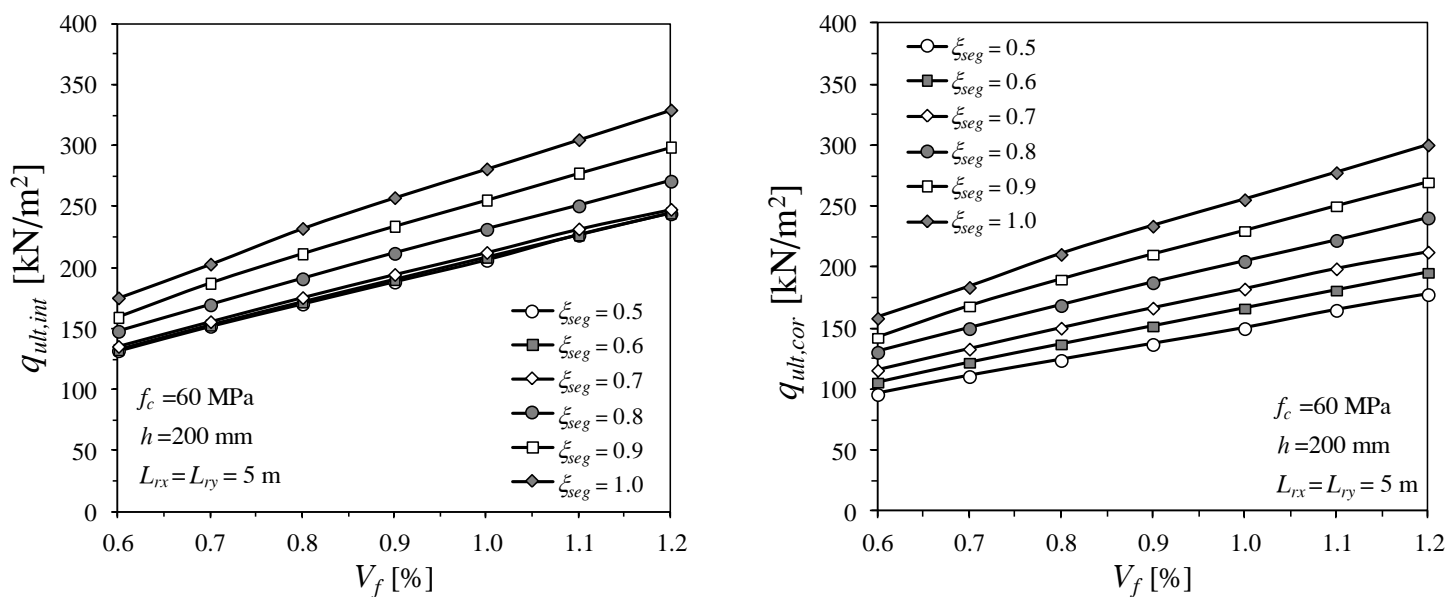
Fig. 26: Influence of the volume percentage of fibres on the ultimate uniform load applied to the panel of E-SFRC slab at: (a) interior, and (b) corner

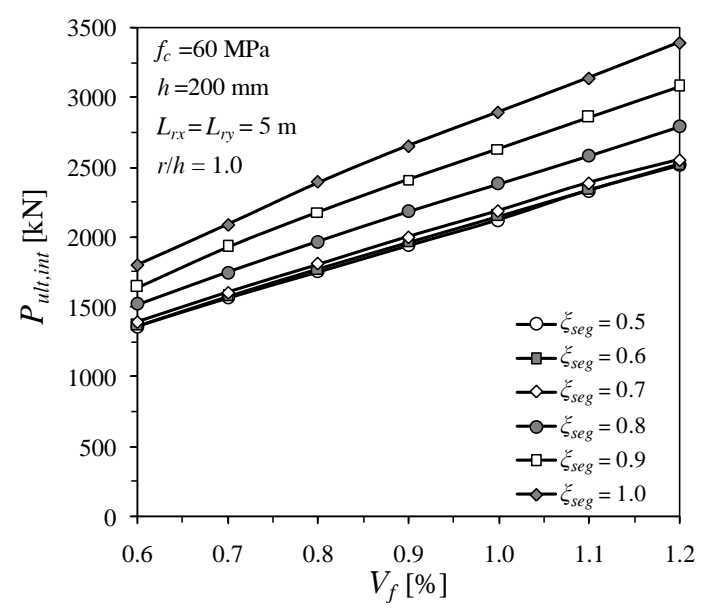

(a)

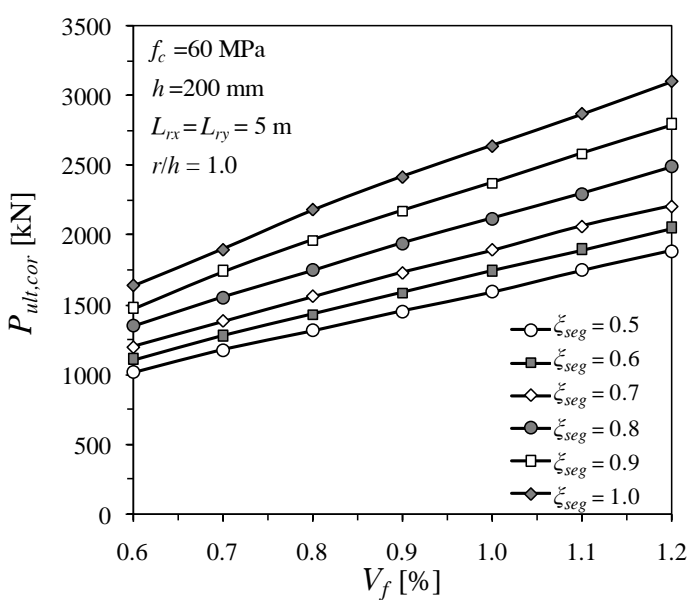

(b)

Fig. 27: Influence of the volume percentage of fibres on the ultimate quasi-point load applied to the panel of E-SFRC slab at (a) interior, and (b) corner

According to Fig. 26(a) and 27(a), the influence of the fibres segregation when ranging between 0.5 and 0.7 is almost marginal on the ultimate load of the interior panels. Fig. 25 shows that for this range of variation of the $\xi_{\text {seg }}$ parameter, the linear increase in the positive plastic moment is neutralised by the linear reduction in the negative plastic moment. Therefore, for this case Eqs. (1) and (3) lead a marginal increase in the load carrying capacity of the interior panels. However, for values of the $\xi_{\text {seg }}$ parameter larger than 0.7 , the negative plastic moment of the section remains constant, while the positive plastic moment is increasing almost linearly, leading to a significant increase of the ultimate load of the interior panel. Due to the simply support conditions assumed for the free edges of the corner panels, the contribution of the negative plastic moment on the ultimate load is not so significant as it is in the interior panels, and, consequently, the ultimate load of the corner panel increases more pronouncedly with the fibres segregation (Fig. 26b and 27b).

\subsection{Influence of the height of cross section}


The influence of the height of slab's cross section on the ultimate uniform and concentrated load of E-SFRC slab is represented in Figs. 28 and 29, respectively. For the considered values of intervening parameters, the load carrying capacity of the ESFRC slab is increased almost four times by the increase in the height of the slab's cross section from $150 \mathrm{~mm}$ to $350 \mathrm{~mm}$.

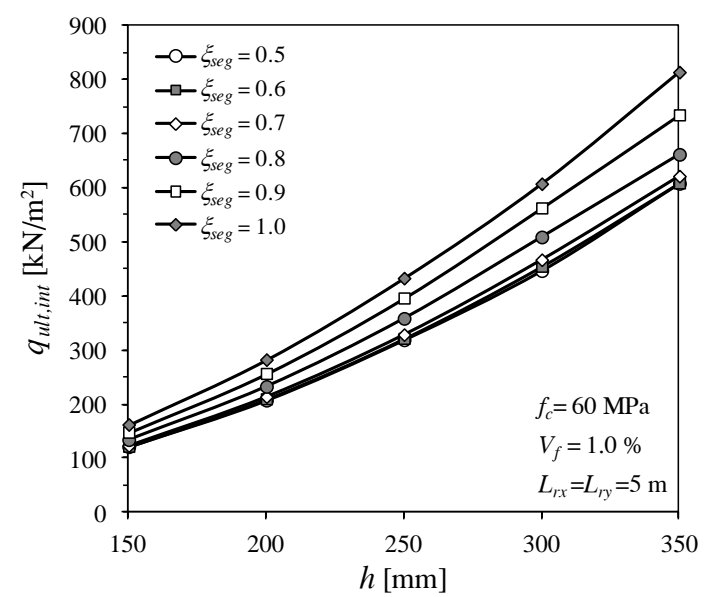

(a)

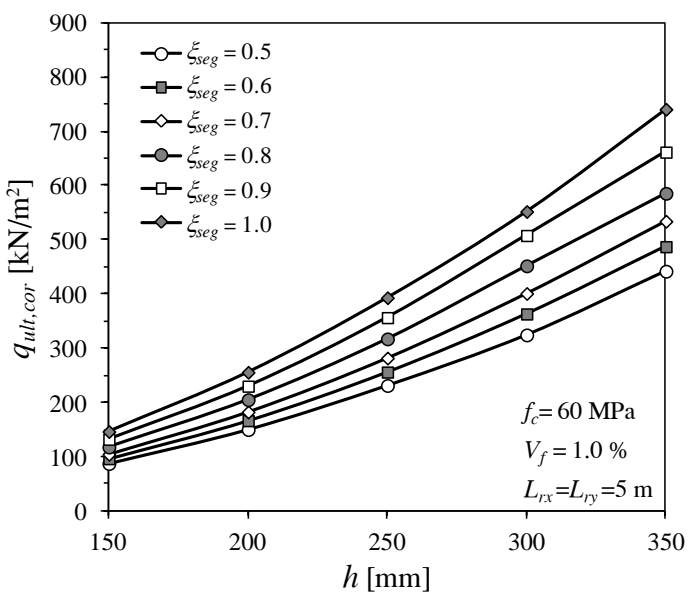

(b)

Fig. 28: Influence of the height of slab's cross section on the ultimate uniform load applied to the panel of E-SFRC slab at (a) interior, and (b) corner

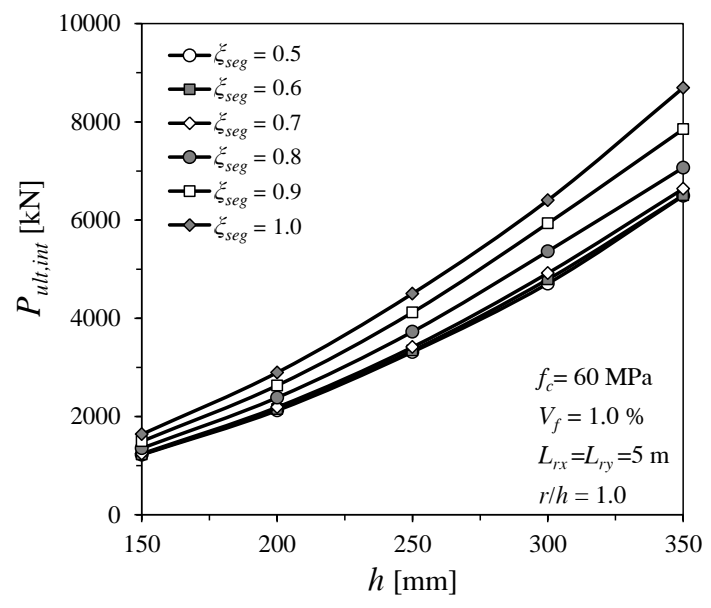

(a)

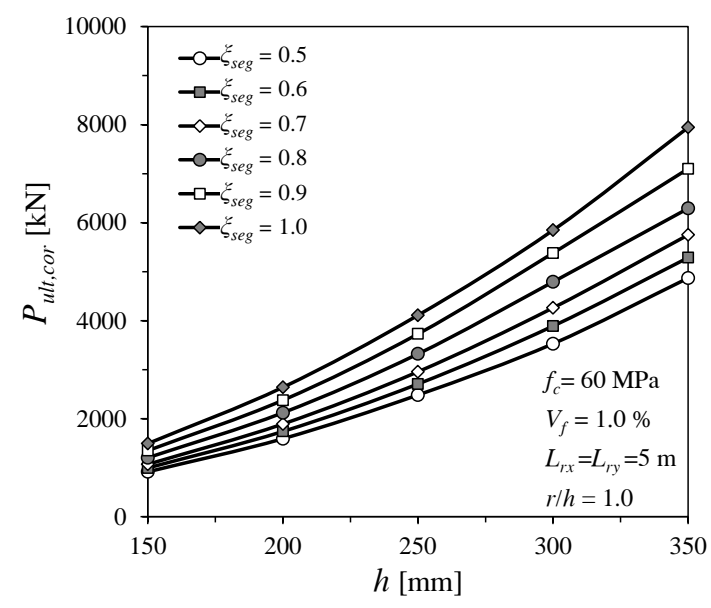

(b)

Fig. 29: Influence of height of slab's cross section on the ultimate quasi-point load applied to the panel of E-SFRC slab at (a) interior, and (b) corner

\subsection{Influence of the concrete compressive strength}


Figs. 30 and 31 show that the load carrying capacity of the E-SFRC slab under uniformly distributed load and quasi-point load increases with the concrete compressive strength. The increase of the ultimate load of the interior and corner panels is around two times when compressive strength of concrete increases from $30 \mathrm{MPa}$ to $80 \mathrm{MPa}$.

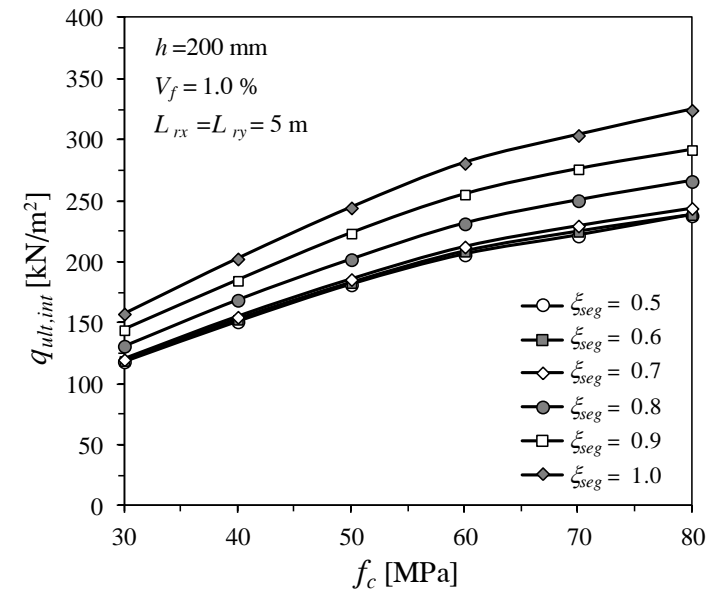

(a)

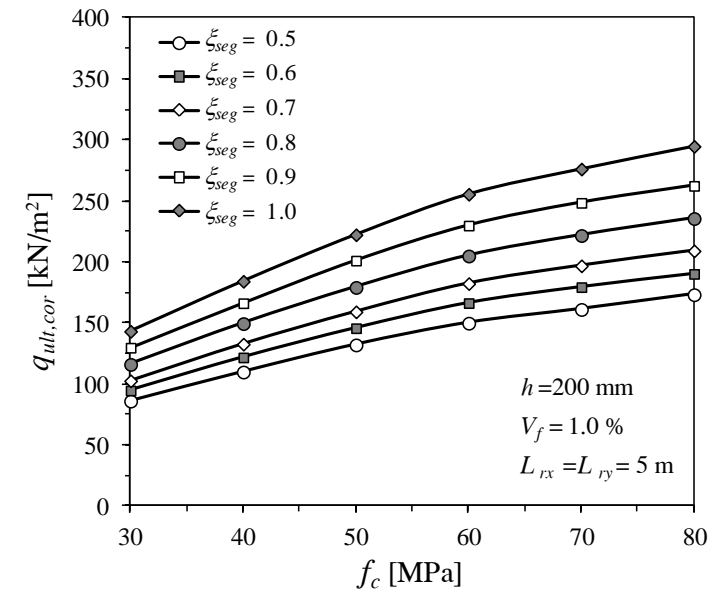

(b)

Fig. 30: Influence of the concrete compressive strength on the ultimate uniform load applied to the panel of E-SFRC slab at (a) interior, and (b) corner

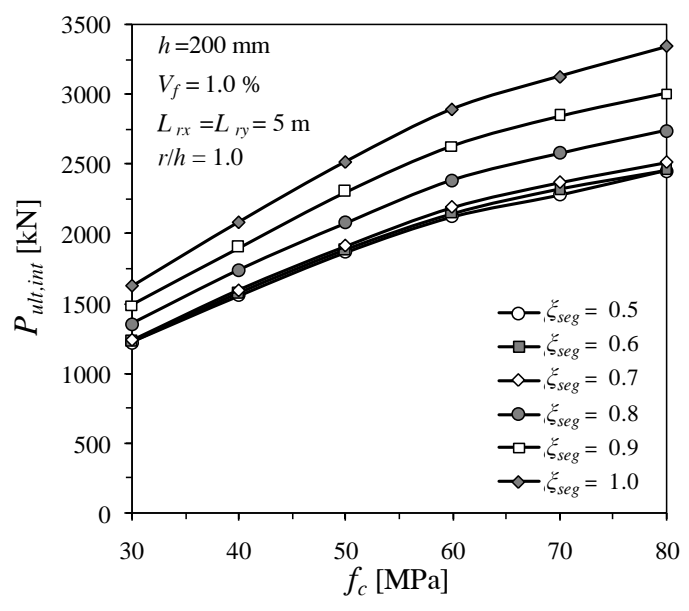

(a)

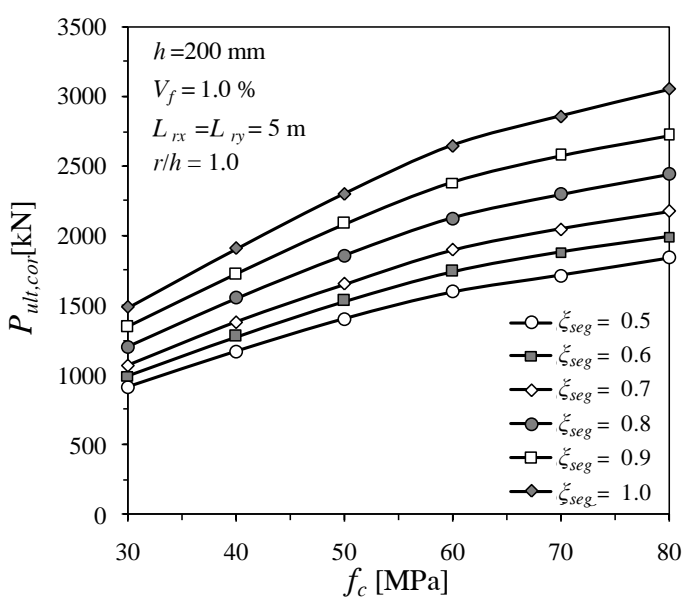

(b)

Fig. 31: Influence of the concrete compressive strength on the ultimate quasi-point load applied to the panel of E-SFRC slab at (a) interior, and (b) corner

\subsection{Influence of the effective span length}


Fig. 32 represents the decrease of the ultimate uniformly distributed load of the E-SFRC slab with the increase of the span's effective length of the panel. For the considered values of the intervening parameters, a reduction of about seven times is achieved in the ultimate uniformly distributed load of the interior and corner panel when the effective span length of the slab increases from $2.5 \mathrm{~m}$ to $7 \mathrm{~m}$. However, Fig. 33 shows that for the same increment of the span's effective length, the reduction of the slab's load carrying capacity under quasi-point load does not exceed $7 \%$.

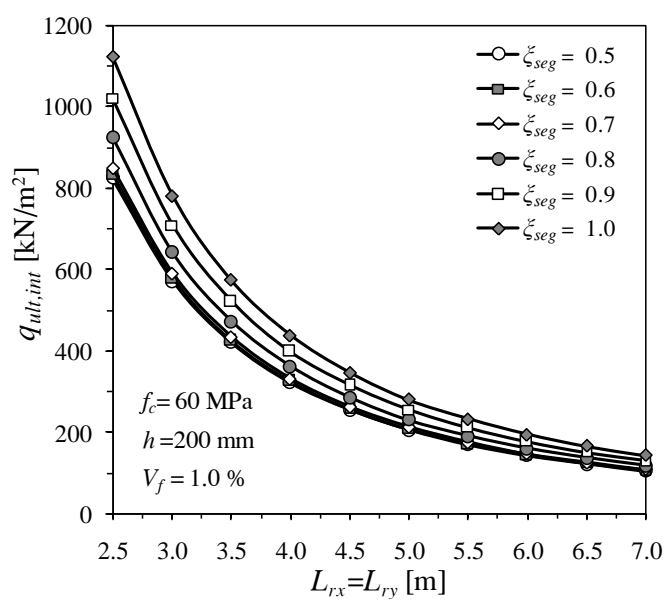

(a)

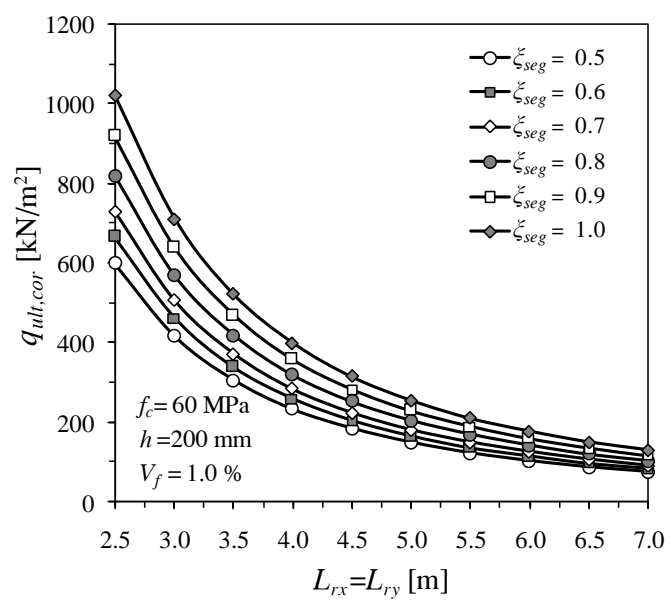

(b)

Fig. 32: The influence of the panel span length on the ultimate uniformly distributed load applied to the panel of E-SFRC slab at (a) interior, and (b) corner

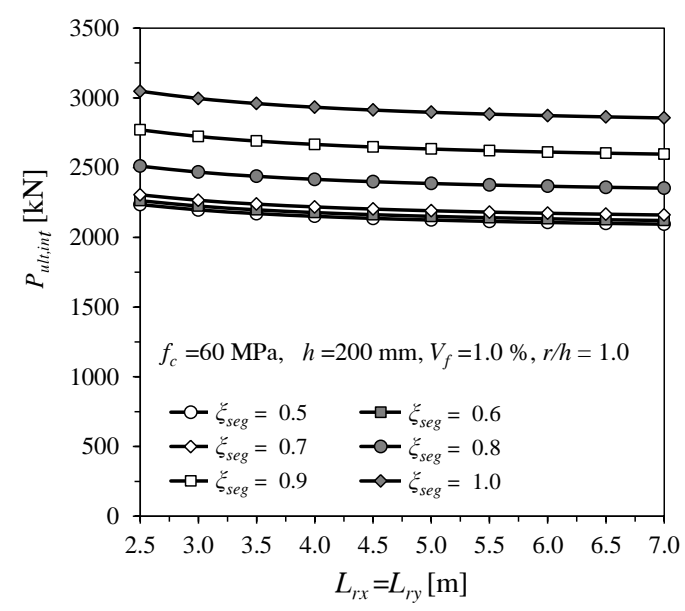

(a)

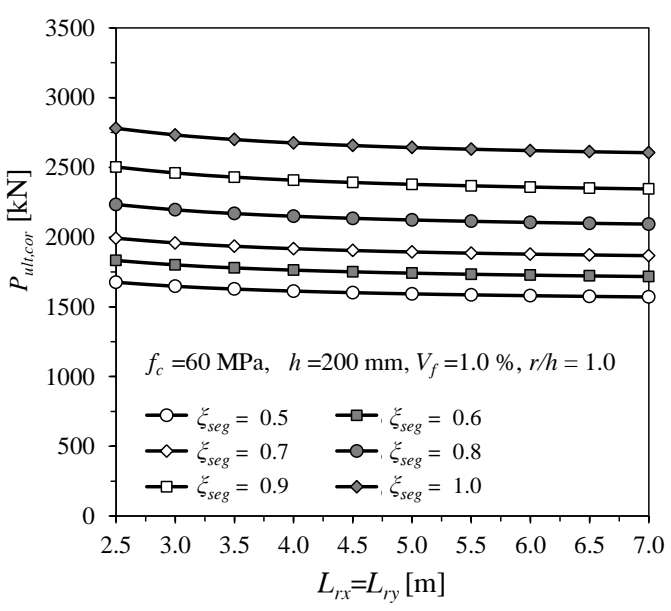

(b)

Fig. 33: The influence of the panel span length on the ultimate quasi-point load applied to the panel of E-SFRC slab at (a) interior, and (b) corner 


\section{Conclusions}

In the present paper, a novel methodology was presented to take into account the volume fraction of the fibres, as well as the fibres segregation degree parameter to determine the positive and negative plastic bending moment per unit width of the ESFRC slab's cross section. The determined plastic moments were used in equations developed based on the yield line theory to predict the load carrying capacity of the interior and corner panels of E-SFRC slab under uniformly distributed and quasi-point loads. The predictive performance of the proposed model was assessed by the FEM simulation of the E-SFRC slab system.

The developed model was used in a parametric study, in which the influence of the most relevant intervening parameters was evaluated on the load carrying capacity of the ESFRC slabs. The obtained results demonstrated an increase of $80 \%$ of the load carrying capacity of the E-SFRC slab with the increase in the volume fraction of fibres from $0.6 \%$ to $1.2 \%$, regardless of the load configuration and position of the loaded panel. It was also revealed that the load carrying capacity of the E-SFRC slab is increased, in general, with the increase in the fibres segregation parameter $\left(\xi_{\text {seg }}\right)$. This means that considering a uniform dispersion of fibres on the height of slab's cross section is a conservative assumption in a design methodology. Nevertheless, when $\xi_{\text {seg }}$ parameter ranges between 0.5 and 0.7 , its influence on the load carrying capacity of the interior panel is marginal. For the range of variables considered in the performed parametric study, the ultimate load of the E-SFRC slab increased two times when the compressive strength of concrete augmented from $30 \mathrm{MPa}$ to $80 \mathrm{MPa}$. Furthermore, an increase of four times was obtained for the ultimate load when the height of the slab's cross section increased from $150 \mathrm{~mm}$ to $350 \mathrm{~mm}$. A reduction of around 7 times of the ultimate uniformly distributed load of the interior and corner panel was obtained with the increase of the span's effective length of the slab from $2.5 \mathrm{~m}$ to $7 \mathrm{~m}$, while for the same increment of the span's effective length, the reduction of the load carrying capacity of slab under quasi-point load is restricted to $6.5 \%$.

\section{Acknowledgements}

This work is supported by FEDER funds through the Operational Program for Competitiveness Factors - COMPETE and National Funds through FCT - Portuguese 
Foundation for Science and Technology under the project "SlabSys - HFRC - Flat slabs for multi-storey buildings using hybrid reinforced self-compacting concrete: an innovative structural system" PTDC/ECM/120394/2010. The first author also acknowledges the financial supports provided by Seismic Geotechnical and High Performance Concrete Research Centre of Semnan Branch, Islamic Azad University.

\section{References}

[1] Salehian H, Barros JAO, Taheri M. Evaluation of the influence of post-cracking response of steel fibre reinforced concrete (SFRC) on load carrying capacity of SFRC panels. Construction and Building Materials. 2014;73:289-304.

[2] Salehian H, Barros JAO. Assessment of the performance of steel fibre reinforced selfcompacting concrete in elevated slabs. Cement and Concrete Composites. 2015;55:268-80.

[3] Salehian H. Evaluation of the Performance of Steel Fibre Reinforced Self-Compacting Concrete in Elevated Slab Systems; from the Material to the Structure: University of Minho, 2015.

[4] Sasani M, Sagiroglu S. Progressive Collapse of Reinforced Concrete Structures: A Multihazard Perspective. ACl structural journal. 2008;105:96-103.

[5] Barros JAO, Figueiras JA. Experimental behaviour of fibre concrete slabs on soil. Mechanics of Cohesive-frictional Materials. 1998;3:277-90.

[6] Pereira E, Barros J, Camões A. Steel Fiber-Reinforced Self-Compacting Concrete: Experimental Research and Numerical Simulation. Journal of Structural Engineering. 2008;134:1310-21.

[7] Destrée X, Mandl J. Steel Fiber Only Reinforced Concrete in Free Suspended Elevated Slabs: Case Studies, Design Assisted by Testing Route, Comparison to the Latest SFRC Standard 
Documents. In: Walraven J, Stoelhorst D, editors. International FIB 2008 Symposium: CRC Press; 2008. p. 111.

[8] Baumann R, Weisgerber F. Yield-Line Analysis of Slabs-on-Grade. Journal of Structural Engineering. 1983;109:1553-68.

[9] Ingerslev A. Om en elementær beregningsmetode af krydsarmerede plader (On a Simple Analysis of Two-Way Slabs). Ingeniøren. 1921;30:507-15.

[10] Johansen KW. Beregning af krydsarmerede jernbetonpladers brudmoment Bygningsstatiske Meddelelser. 1931;3:1-18.

[11] Johansen KW. Yield-line theory: Cement and Concrete Association London, 1962.

[12] Barros JAO, Gouveia-Gouveia A, Sena-Cruz JM, Azevedo AFM, Antunes JAB. Design methods for steel fibre reinforced concrete industrial floors. Third International Conference of Construction Materials: Performance, Innovations and Structural Implications. Vancouver, Canada2005.

[13] Michels J, Waldmann D, Maas S, Zürbes A. Steel fibers as only reinforcement for flat slab construction - Experimental investigation and design. Construction and Building Materials. 2012;26:145-55.

[14] Ferrara L, Park Y, Shah SP. Correlation among Fresh State Behavior, Fiber Dispersion, and Toughness Properties of SFRCs. Journal of Materials in Civil Engineering. 2008;20:493-501.

[15] Teixeira MDE, Barros JAO, Cunha VMCF, Moraes-Neto BN, Ventura-Gouveia A. Numerical simulation of the punching shear behaviour of self-compacting fibre reinforced flat slabs. Construction and Building Materials. 2015;74:25-36.

[16] Gesund H, Dikshit OP. Yield Line Analysis of the Punching Problem at Slab/Column Intersections. Special Publication. 1971;30.

[17] Gesund H, Kaushik YP. Yield Line Analysis of Punching Failures in Slabs. International Association for Bridge and Structural Engineering. 1970:41-60.

[18] Destrée X. Structural application of steel fibres as only reinforcing in free suspended elevated slabs: conditions - Design examples. In: di Prisco M, Felicetti R, Plizzari GA, editors. Sixth RILEM symposium on fibre-reinforced concretes (BEFIB 2004). Varenna: RILEM; 2004. p. 1073-82.

[19] Barros JAO, Moraes Neto BN, Melo GSSA, Frazão CMV. Assessment of the effectiveness of steel fibre reinforcement for the punching resistance of flat slabs by experimental research and design approach. Composites Part B: Engineering. 2015;78:8-25.

[20] CEB. Comité européen du béton, Annexes aux recommandations internationales pour le calcul et l'execution des ouvrages en béton: dalles et structures planes: structures hyperstatiques. Rome, Italy: Associazione italiana tecnico-economica del cemento, 1972.

[21] Clarke LA, Cope RJ. Concrete Slabs: Analysis and design: Taylor \& Francis, 1984.

[22] Abrishambaf A, Barros JAO, Cunha VMCF. Relation between fibre distribution and postcracking behaviour in steel fibre reinforced self-compacting concrete panels. Cement and Concrete Research. 2013;51:57-66.

[23] Barros JAO, Antunes JAB. Experimental characterization of the flexural behaviour of steel fibre reinforced concrete according to RILEM TC 162-TDF recommendations. In: Schnütgen B, Vandewalle L, editors. International RILEM Workshop on Test and Design Methods for Steel fibre Reinforced Concrete: RILEM Publications SARL; 2003. p. 77-89.

[24] Babut R. Structural investigation of steel fibre reinforced concrete. Heron - Fracture mechanics and structural aspects of concrete. 1986;31:29-44.

[25] Grünewald S. Performance-based design of self-compacting fibre reinforced concrete. The Netherlands: Delft University of Technology, 2004.

[26] Diamond S, Huang J. The ITZ in concrete - a different view based on image analysis and SEM observations. Cement and Concrete Composites. 2001;23:179-88. 
[27] Ozyurt N, Mason TO, Shah SP. NON-DESTRUCTIVE MONITORING OF FIBER DISPERSION IN FRCS USING AC-IMPEDANCE SPECTROSCOPY. In: Konsta-Gdoutos $M$, editor. Measuring, Monitoring and Modeling Concrete Properties: Springer Netherlands; 2006. p. 285-90.

[28] Naaman AE, Moavenzadeh F, McGarry FJ. Probabilistic Analysis of Fiber-Reinforced Concrete. Journal of the Engineering Mechanic's Division - ASCE. 1974;100:397-413.

[29] Kameswara Rao CVS. Effectiveness of random fibres in composites. Cement and Concrete Research. 1979;9:685-93.

[30] Kooiman AG. Modelling steel fibre reinforced concrete for structural design: Delft University of Technology, 2000.

[31] Lappa L. High Strength Fibre Reinforced Concrete: Static and fatigue behavior in bending. Delf, The Netherlands: Delft University of Technology, 2007.

[32] Naaman AE. High Performance Fiber Reinforced Cement Composites In: Shi C, Mo YL, editors. High-Performance Construction Materials - Science and Applications: World Scientific Publishing Co. Pte. Ltd.; 2008.

[33] Barros JAO, Pereira E, Santos S. Lightweight Panels of Steel Fiber-Reinforced SelfCompacting Concrete. Journal of Materials in Civil Engineering. 2007;19:295-304.

[34] EN 206-1. Concrete - Part 1: Specification, performance, production and conformity. . 2000:69.

[35] fib Model Code 2010. CEB and FIP - Final Draft, 2011.

[36] Taheri M, Barros JAO, Salehian H. Parametric Study of the Use of Strain Softening/Hardening FRC for RC Elements Failing in Bending. Journal of Materials in Civil Engineering. 2012;24:259-74.

[37] Barros JAO, Taheri M, Salehian H, Mendes PJD. A design model for fibre reinforced concrete beams pre-stressed with steel and FRP bars. Composite Structures. 2012;94:2494512.

[38] Barros JAO, Taheri M, Salehian H. A model to simulate the moment-rotation and crack width of FRC members reinforced with longitudinal bars. Engineering Structures. 2015;100:4356.

[39] Vipulanandan C, Paul E. Performance of epoxy and polyester polymer concrete. ACl Materials Journal. 1990;87:241-51.

[40] Barros J, Figueiras J. Flexural Behavior of SFRC: Testing and Modeling. Journal of Materials in Civil Engineering. 1999;11:331-9.

[41] Van Mier JGM. Fracture Processes of Concrete: CRC Press, 1997.

[42] Hillerborg A, Modéer M, Petersson PE. Analysis of crack formation and crack growth in concrete by means of fracture mechanics and finite elements. Cement and Concrete Research. 1976;6:773-81.

[43] Taheri M, Barros JAO, Salehian H. A design model for strain-softening and strainhardening fiber reinforced elements reinforced longitudinally with steel and FRP bars. Composites Part B: Engineering. 2011;42:1630-40.

[44] Azevedo AFM, Barros JAO, Sena-Cruz JM, Gouveia AV. Educational software for the design of structures. In: Gomes JS, Afonso CF, António CC, Matos AS, editors. Proceedings of III Congresso de Luso- Moçambicano de Engenharia. Maputo, Mozambique2003. p. 81-92.

[45] Ventura-Gouveia A, Barros JAO, Azevedo AFM. Crack constitutive model for the prediction of punching failure modes of fiber reinforced concrete laminar structures. Computers \& Concrete. 2011;8:735-55.

[46] Bažant ZP, Oh BH. Crack band theory for fracture of concrete. Matériaux et Construction. 1983;16:155-77.

[47] Oliver J. A consistent characteristics length for smeared cracking models. International Journal for Numerical Methods in Engineering. 1989;28:461-74. 


\section{Appendix A:}

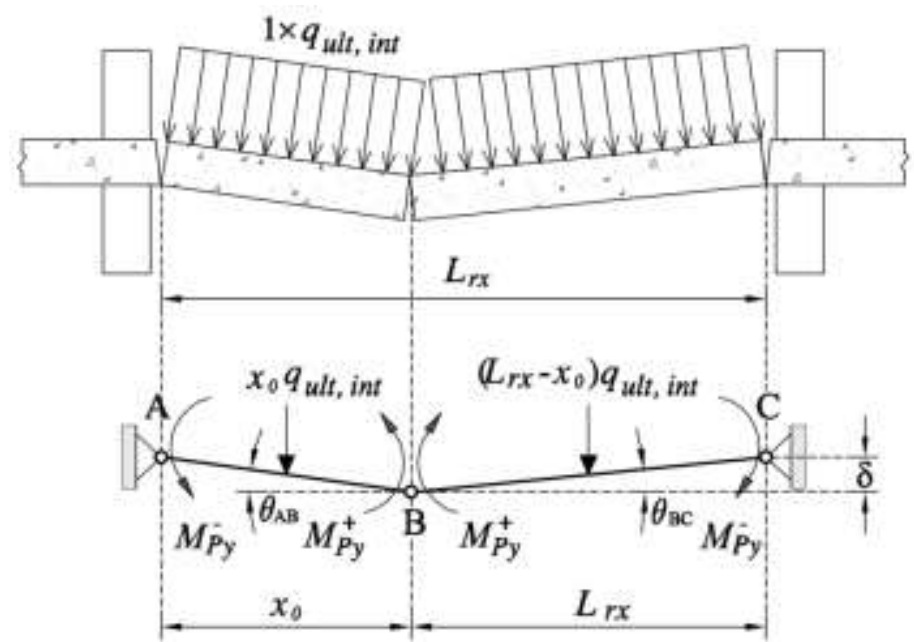

Fig. A.1: Deformation of an interior panel of the elevated slab submitted to uniformly distributed load

Deformation of an interior panel of elevated slab under uniformly distributed load of $q_{u l t, \text { int }}$ is depicted in Fig. A.1 where the effective span of the slab is subdivided into AB and $\mathrm{BC}$ segments with overall rigid rotation of $\theta_{A B}$ and $\theta_{B C}$, respectively. According to Fig. A.1 which the internal work $\left(W_{I}\right)$ and the external work $\left(W_{E}\right)$ executed for the slab's unit width cross section are obtained by the following equations:

For segment AB: $\left\{\begin{array}{l}W_{I}=M_{P y}^{-}\left(\theta_{A B}\right)+M_{P y}^{+}\left(\theta_{A B}\right) \\ W_{E}=\left(1 \times q_{u l t, \text { int }}\right) x_{0} \frac{\delta}{2}\end{array}\right.$
For segment BC: $\left\{\begin{array}{l}W_{I}=M_{P y}^{-}\left(\theta_{B C}\right)+M_{P y}^{+}\left(\theta_{B C}\right) \\ W_{E}=\left(1 \times q_{u l t, \text { int }}\right)\left(L_{r x}-x_{0}\right) \frac{\delta}{2}\end{array}\right.$

where $x_{0}$ is the distance of the positive yield line with respect to the negative yield line at the left extremity, $L_{r x}$ is the effective length of the slab's span in the $x$ direction, and $M_{P y}^{+}$and $M_{P y}^{-}$are the positive and negative plastic moments of the unit width of the slab's cross section along the $y$ direction, respectively. Furthermore, $\delta\left(=x_{0} \theta_{A B}=\left(L_{r x}-x_{0}\right) \theta_{B C}\right)$ is the deflection of the slab at the positive yield line. By equating the external work and the internal work it can be written: 


$$
\begin{array}{ll}
M_{P y}^{+}\left(1+\varphi_{h y}\right)=\frac{q_{u l t, \text { int }} x_{0}^{2}}{2} & \text { (for segment AB) } \\
M_{P y}^{+}\left(1+\varphi_{h y}\right)=\frac{q_{u l t, \text { int }}\left(L_{r x}-x_{0}\right)^{2}}{2} & \text { (for segment BC) }
\end{array}
$$

where $\varphi_{h y}$ is the ratio of the negative to the positive plastic moment $\left(M_{P y}^{-} / M_{P y}^{+}\right)$in the $y$ direction. By solving Eqs (A.5) and (A.6) the $x_{0}$ parameter of $0.5 L_{r x}$ is determined. Then by substituting $x_{0}$ into Eq. (A.5), it can be rewritten:

$$
q_{u l t, \text { int }}=\frac{8 M_{P y}^{+}\left(1+\varphi_{h y}\right)}{L_{r x}^{2}}
$$

Similarly, the slab's positive plastic moment of the slab's cross section in the $x$ direction is determined by the following equation:

$$
q_{u l t, \text { int }}=\frac{8 M_{P x}^{+}\left(1+\varphi_{h x}\right)}{L_{r y}{ }^{2}}
$$

where $L_{r y}$ is the effective length of the slab's span in the $y$ direction, and $M_{P x}^{+}$and $M_{P x}^{-}$are the positive and negative plastic moments of the unit width of slab's cross section along the $x$ direction. The minimum values of the uniform load determined from Eqs. (A.7) and (A.8) is considered as the ultimate uniformly distributed load of the interior panel:

$$
q_{u l t, \text { int }}=\min \left[\frac{8 M_{P x}^{+}\left(1+\varphi_{h x}\right)}{L_{r y}{ }^{2}}, \frac{8 M_{P y}^{+}\left(1+\varphi_{h y}\right)}{L_{r x}{ }^{2}}\right]
$$




\section{Appendix B: Load Carrying Capacity of a Corner Panel of the E-Slab under Uniform Load}

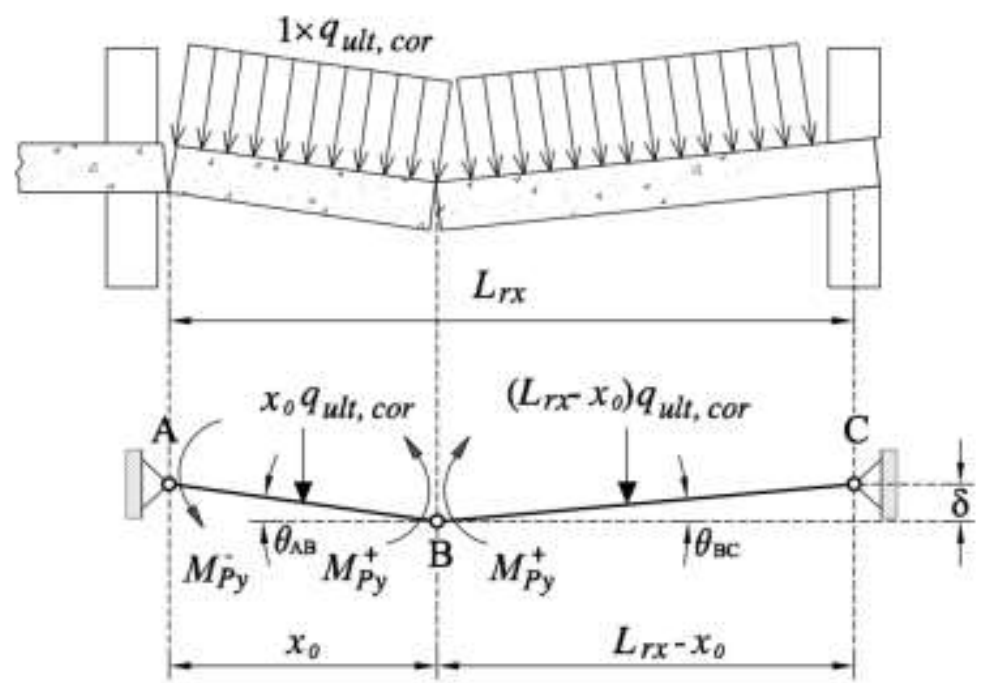

Fig. B.1: Deformation of a corner panel of the elevated slab submitted to uniformly distributed load

In Fig. B.1 deformation of a corner panel of the elevated slab subjected to a uniformly distributed load of $q_{u l t, c o r}$ are depicted. Accordingly, the internal work $\left(W_{I}\right)$ and the external work $\left(W_{E}\right)$ accomplished for the slab's unit width cross section can be obtained by the following equations:

$$
\begin{aligned}
& \text { For segment AB: }\left\{\begin{array}{l}
W_{I}=M_{P y}^{-}\left(\theta_{A B}\right)+M_{P y}^{+}\left(\theta_{A B}\right) \\
W_{E}=\left(1 \times q_{u l t, \text { cor }}\right) x_{0} \frac{\delta}{2}
\end{array}\right. \\
& \text { For segment BC: }\left\{\begin{array}{l}
W_{I}=M_{P y}^{+}\left(\theta_{B C}\right) \\
W_{E}=\left(1 \times q_{u l t, c o r}\right)\left(L_{r x}-x_{0}\right) \frac{\delta}{2}
\end{array}\right.
\end{aligned}
$$

where the intervening parameters have the same meaning explained before. By adopting the principles of the work method, Eqs. (B.5) and (B.6) are obtained by equating the external work and the internal work for the $\mathrm{AB}$ and $\mathrm{BC}$ segments, respectively:

$$
M_{P y}^{-}+M_{P y}^{+}=\frac{q_{u l t, c o r} x_{0}^{2}}{2} \quad \text { (for segment AB) }
$$




$$
M_{P y}^{+}=\frac{q_{u l t, c o r}\left(L_{r x}-x_{0}\right)^{2}}{2} \quad \text { (for segment BC) }
$$

Eq. (B.5) can be deduced to:

$$
M_{P y}^{+}\left(1+\varphi_{h y}\right)=\frac{q_{u l t, c o r} x_{0}^{2}}{2} \quad \text { (for segment AB) }
$$

By solving Eqs. (B.6) and (B.7) the $x_{0}$ parameter is determined by the following equation:

$$
x_{0}=L_{r x}\left(\frac{\sqrt{\left(1+\varphi_{h y}\right)}}{\sqrt{\left(1+\varphi_{h y}\right)}+1}\right)
$$

By substituting $x_{0}$ into Eq. (B.7), it can be rewritten:

$$
q_{u l t, c o r}=\frac{2 M_{P y}^{+}\left(1+\sqrt{\left(1+\varphi_{h y}\right)}\right)^{2}}{L_{r x}^{2}}
$$

Similarly, regarding the yield lines propagate along the $x$ direction it can be written:

$$
q_{u l t, c o r}=\frac{2 M_{P x}^{+}\left(1+\sqrt{\left(1+\varphi_{h x}\right)}\right)^{2}}{L_{r y}{ }^{2}}
$$

The minimum values of the uniform load determined from Eqs. (B.9) and (B.10) is considered as the ultimate uniformly distributed load of the interior panel:

$$
q_{u l t, c o r}=\min \left[\frac{2 M_{P x}^{+}\left(\sqrt{\left(1+\varphi_{h x}\right)}+1\right)^{2}}{L_{r y}{ }^{2}}, \frac{2 M_{P y}^{+}\left(\sqrt{\left(1+\varphi_{h y}\right)}+1\right)^{2}}{L_{r x}{ }^{2}}\right]
$$




\section{Appendix C: Load Carrying Capacity of an Interior Panel of the E-Slab Under}

\section{Concentric Load}

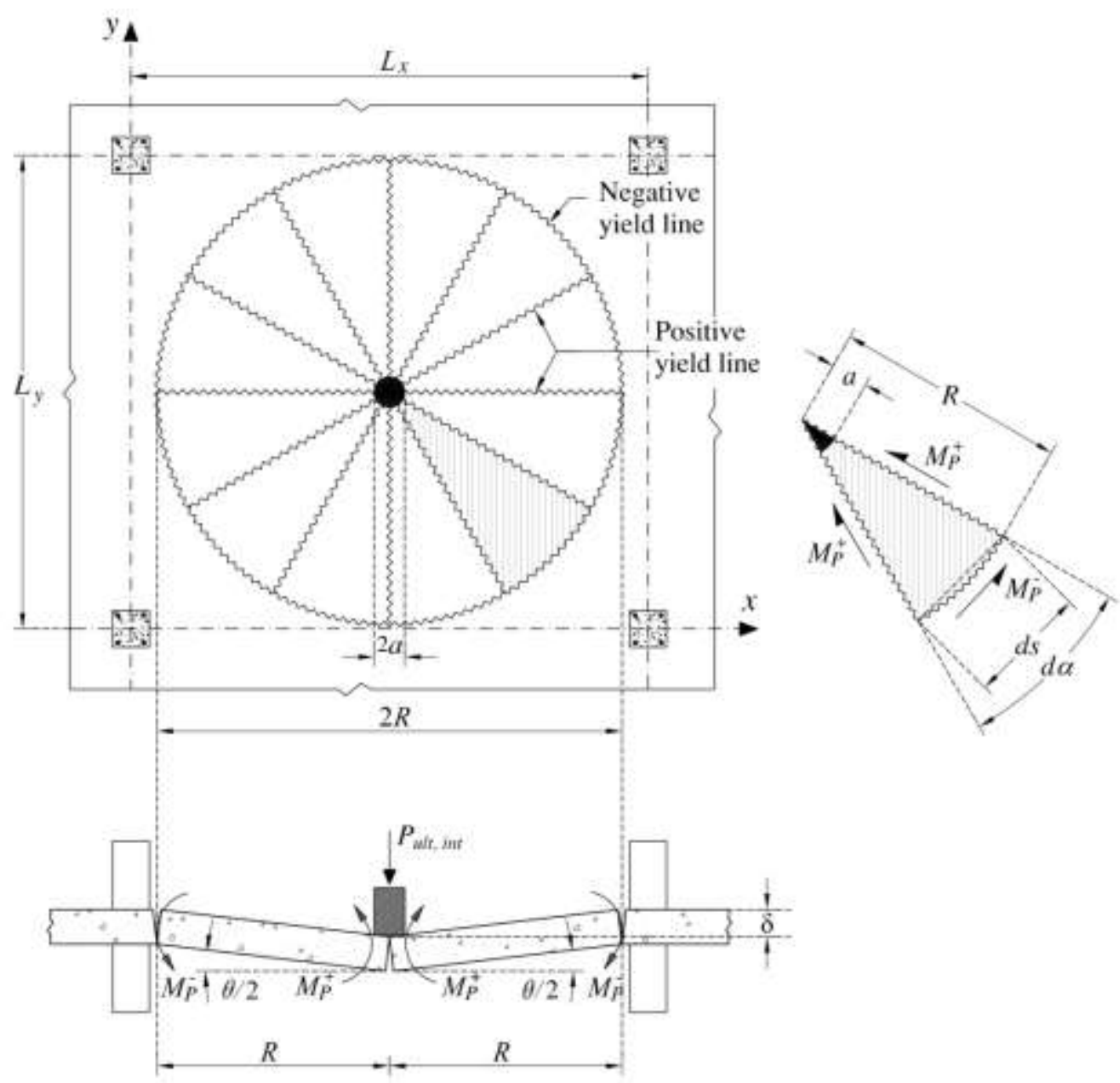

Fig. C.1: The yield lines and deformation of an interior panel of the elevated slab submitted to a concentric load

In Fig. C.1 the yield lines of an interior panel of elevated slab subjected to a concentric load of $P_{u l t \text {,int }}$ are depicted, according to which the external and internal work, $\left(d W_{E}\right.$ and $d W_{I}$, respectively) corresponding to a finite sector with angle of $d \alpha$ is determined by the following equations:

$$
d W_{I}=M_{P}^{+} R \theta d \alpha+2\left(M_{P}^{-} R \theta \frac{d \alpha}{2}\right)
$$




$$
d W_{E}=\left[\left(\frac{P_{u l t, \text { int }}}{\pi a^{2}}\right)\left(\frac{\pi a^{2}}{2 \pi}\right) \delta\right] d \alpha
$$

where, $a$ is the radius of the concentric load, $R$ is the radius of the negative yield line, $\theta$ is the overall rotation of the positive yield line, and $\delta$ is the deflection of the centre of the loaded area of the considered finite sector by Eq. (C.3):

$$
\delta=\left(R-\frac{2}{3} a\right) \theta
$$

By substituting Eq. (C.3) and designating the ratio of the negative to the positive plastic moment by $\varphi_{h}$, the total internal and external works are determined from Eqs.(C.4) and (C.5), respectively:

$$
\begin{aligned}
& W_{I}=\int_{0}^{2 \pi} M_{P}^{+}\left(1+\varphi_{h}\right) R \theta d \alpha \\
& W_{E}=\int_{0}^{2 \pi}\left(\frac{P_{u l t, \text { int }}}{2 \pi}\right)\left(R-\frac{2}{3} a\right) \theta d \alpha
\end{aligned}
$$

By adopting the work method the external and internal works are equated leading to Eq. (C.6):

$$
P_{u l t, \text { int }}=\frac{2 \pi M_{P}^{+}\left(1+\varphi_{h}\right)}{\left(1-\frac{2}{3} \times \frac{a}{R}\right)}
$$




\section{Appendix D: Load Carrying Capacity of a Corner Panel of the E-Slab under}

\section{Concentric Load}

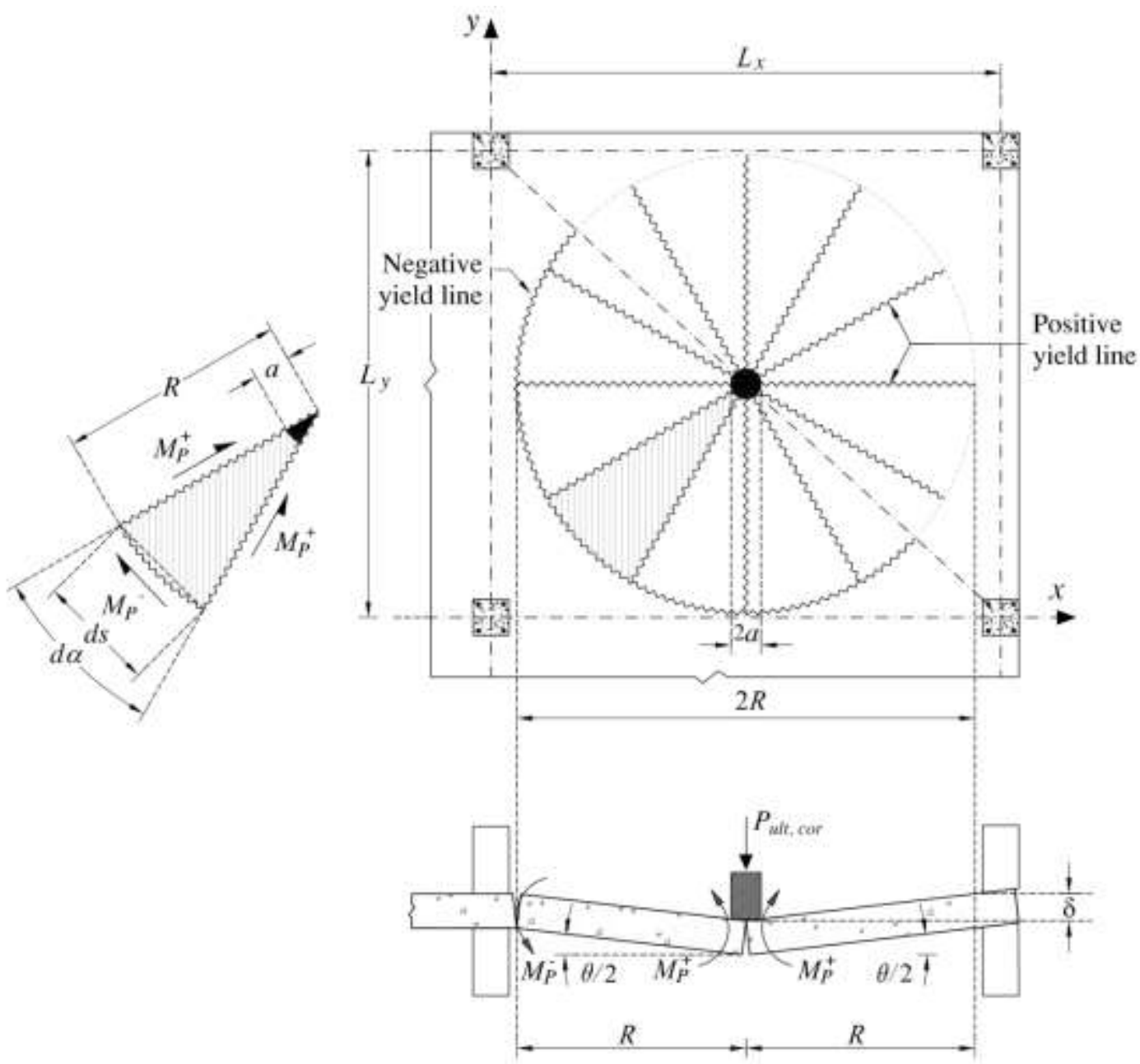

Fig. D.1: The yield lines and deformation of a corner panel of the elevated slab submitted to a concentric load

In Fig. D.1 the yield lines of an interior panel of elevated slab subjected to a concentric load of $P_{u l t \text {,int }}$ are depicted, according to which the external and internal work, ( $d W_{E}$ and $d W_{I}$, respectively) corresponding to a finite sector with angle of $d \alpha$ is determined by the following equations:

$$
\begin{aligned}
d W_{I} & =M_{P}^{+} R \theta d \alpha+2\left(M_{P}^{-} R \theta \frac{d \alpha}{2}\right) \\
d W_{E} & =\left[\left(\frac{P_{u l t, \text { int }}}{\pi a^{2}}\right)\left(\frac{\pi a^{2}}{2 \pi}\right) \delta\right] d \alpha
\end{aligned}
$$


where, $a$ is the radius of the concentric load, $R$ is the radius of the negative yield line, $\theta$ is the overall rotation of the positive yield line, and $\delta$ is the deflection of the centre of the loaded area of the considered finite sector by Eq. (D.3):

$$
\delta=\left(R-\frac{2}{3} a\right) \theta
$$

By substituting Eq. (D.3), the total internal and external works are determined by Eqs. (D.4) and (D.5), respectively:

$$
\begin{aligned}
& W_{I}=\int_{0}^{2 \pi} M_{P}^{+} R \theta d \alpha+\int_{0}^{\pi} M_{P}^{-} R \theta d \alpha \\
& W_{E}=\int_{0}^{2 \pi}\left(\frac{P_{u l t, \text { int }}}{2 \pi}\right)\left(R-\frac{2}{3} a\right) \theta d \alpha
\end{aligned}
$$

By adopting the work method the external and internal works are equated leading to Eq. (D.6):

$$
P_{u l t, c o r}=\frac{2 \pi M_{P}^{+}\left(1+0.5 \varphi_{h}\right)}{\left(1-\frac{2}{3} \times \frac{a}{R}\right)}
$$

where $\varphi_{h}$ is the ratio of the negative to the positive plastic moment of the slab unit width of cross section. 